Revista de Psicología de la PUCP. Volumen Extraordinario II, 1998

\title{
AMAMANTAMIENTO Y DESARROLLO INFANTIL
}

\author{
Ernesto Pollitt y Patricia Kariger
}

Volumen Extraordinario II, 1998

con motivo de los 40 años de creación de la Especialidad de

Psicología de la Pontificia Universidad Católica del Perú 



\section{PRESENTACIÓN}

Hace un tiempo Ernesto Pollitt sometió a consideración de la Revista la publicación de este interesantísimo trabajo sobre amamantamiento y desarrollo infantil. Acogí su propuesta con mucho entusiasmo debido a la relevancia del tema para la comprensión del desarrollo infantil.

Este trabajo fue presentado en la reunión sobre Amamantamiento, Ciencia y Sociedad que fue organizada por, y tuvo lugar en el local de, la Pontificia Academia de Ciencias del Vaticano entre el 11 y el 13 de mayo de 1995. La Iglesia Católica mantiene un interés activo en los beneficios de la lactancia materna en la salud de la madre y del niño, así como en sus efectos naturales en la regulación de la ovulación de la mujer. En 1996, este estudio y los otros trabajos presentados fueron publicados en inglés, por el Boletín de Alimentación y Nutrición que publica la Universidad de las Naciones Unidas.

Con la debida autorización del Obispo James T. McHugh, organizador de la reunión y del Dr. Nevin Scrimshaw, editor del Boletín, se tradujo el estudio para su publicación en la Revista de Psicología. No sólo se ha incluido el artículo de Ernesto Pollitt y Patricia Kariger, sino también el prólogo, la Audiencia Papal Solemne y el Discurso al Santo Padre, que tuvieron lugar con esta ocasión.

La Revista siempre ha tenido por política publicar articulos originales, no obstante en esta ocasión se ha hecho una excepción. Pensamos que el estudio y las reflexiones vertidas en él son transcendentales, teniendo en cuenta que a pesar de encontrarnos a fines del Siglo XX, siguen sin definirse todas las ventajas y los riesgos asociados a la lactancia materna en nuestro medio y en países en vías de desarrollo.

El nombramiento del Dr. Ernesto Pollitt como Profesor Honorario del Departamento de Humanidades, dentro del marco de las celebraciones de los 40 años de la Especialidad de Psicología, son una ocasión propicia para publicarlo en un volumen extraordinario.

Cecilia Thorne

Directora 



\title{
PRÓlogo
}

Reconociendo los beneficios nutricionales e inmunológicos de la lactancia materna en los bebes y los beneficios de ésta en la salud de las madres, la Pontificia Academia de Ciencias y la Sociedad Real prestaron apoyo a un grupo de trabajo que se reunió en la Ciudad del Vaticano del 11 al 13 de mayo de 1995. El encuentro reunió a un grupo multidisciplinario de científicos comprometidos en la investigación social y biológica y en el estudio clínico de la lactancia. El propósito del encuentro fue el de crear un foro para la presentación de la investigación acumulada y conducir una discusión de alto nivel científico sobre sus implicancias. El Boletín de Alimentación y Nutrición ha brindado la oportunidad de publicar las ponencias y las discusiones, colocándolas asi al alcance de una vasta audiencia. Estamos profundamente agradecidos a los editores por su cooperacion, su asistencia y su paciencia en la preparación de los manuscritos.

Agradecemos igualmente a los participantes por sus estudios y su trabajo para preparar la presentación. Las ponencias y las discusiones consignan información científica al alcance, de modo competente y objetivo. Ellos no reprentan la enseñanza oficial de la Iglesia Católica Romana o la aplicación moral o pastoral de esta enseñanza. Tampoco representan la posición oficial de la Sociedad Real o las políticas del Reino Unido. El objetivo del taller fue lograr una revisión comprensiva que llene los más altos estándares científicos. Confiamos que será de gran valor para eruditos, clínicos y otros que trabajan diariamente para enriquecer la vida de las madres y de los bebes.

\author{
Mons. Renato Dardozzi \\ Pontificia Academia de Ciencias
}

Dra. Ann McLaren

Sociedad Real 



\section{Audiencia Papal Solemne}

En la mañana del 12 de mayo de 1995, Su Santidad Juan Pablo II concedió una Audiencia Solemne en el Palacio Apostólico del Vaticano a los participantes del Grupo de Trabajo sobre "Amamantamiento: Ciencia y Sociedad".

El Grupo, introducido por Su Excelencia Mons. James T. McHugh, Obispo de Camden, New Jersey, USA, fue recibido paternalmente por el Santo Padre, quién al final de la Audiencia saludó a todos los participantes.

El Santo Padre pronunció el siguiente discurso:

Sus Eminencias,

Sus Excelencias,

Señoras y Señores,

1. Como siempre, es un gran placer recibir a los distinguidos prácticantes en las sesiones de estudio organizadas por la Pontificia Academia de Ciencias. Yo agradezco al Obispo James McHugh por sus amables palabras de introducción. Hoy día estoy especialmente contento de hacer extensivo mi aprecio a la Sociedad Real, quien ha patrocinado esta significativa reunión.

Fiel a sus propósitos y estatutos, la Pontificia Academia de Ciencias esta dirigida a una amplia línea de temas científicos, sociales y éticos que tienen relación con el servicio de la Iglesia a la familia humana, un servicio que nace del evangélico mandamiento de amor. La Academia con sus recursos juega un papel ayudando a la Iglesia, en particular a la Santa Sede, a cumplir esta tarea de servicio con el beneficio del mas experto conocimiento y discernimiento científico. Sus estudios e investigaciones contribuyen con el supremo esfuerzo de la Iglesia de transitar de la mano con la humanidad en la senda a través de realidades temporales hacia el gran e inexorable destino transcendente del hombre. 
2. En esta ocasión ustedes han sido invitados a compartir sus experiencias en el tema especifico de "Amamantamiento: Ciencia y Sociedad", como parte de un estudio completo que la Academia ha venido prosiguiendo desde 1990 sobre Población y Recursos. Como cientificos ustedes dirigen sus investigaciones hacia un mejor entendimiento de las ventajas del amamantamiento para el bebé ( 0 a 12 meses) y para la madre. Su Grupo de Trabajo puede confirmar que en circunstancias normales esto incluye dos beneficios mayores para la criatura: protección contra las enfermedades y una correcta alimentación. Mas aun, adicionalmente a estos efectos inmunológicos y nutricionales, este modo natural de alimentación puede crear un vínculo de amor y seguridad entre la madre y la criatura, y permite a esta ultima hacer sentir su presencia como persona a través de la interacción con la madre.

Todo esto es obviamente un asunto de interés inmediato para innumerables mujeres y niños, y algo que evidentemente tiene una importancia en general para todas las sociedades, ricas o pobres. Uno espera que sus estudios puedan servir para realizar la conciencia de como esta actividad beneficia a la criatura y ayuda crear un vinculo materno mas cercano tan necesario para el sano desarrollo de la criatura. Tan humano y natural es este vinculo que los Salmos usan la imagen del niño en el pecho de su madre como una representación del cuidado de Dios hacia el hombre (1). Tan vital es esta interacción entre la madre y el niño que mi predecesor, el Papa Pio XII, urgió a las madres católicas, que de ser posible, alimentaran ellas mismas a sus niños (2). Desde varias perspectivas, por lo tanto, el tema es de interés para la Iglesia, llamada como lo está a interesarse por la salud de la vida y de la familia.

3. Mundialmente las encuestas indican que dos tercios de las madres aun amamantan, al menos en alguna medida. Pero las estadísticas también muestran que se ha producido una caida en el numero de mujeres que alimentan a sus criaturas de esta manera, no solo en paises desarrollados en donde la práctica mayormente debe ser restituida, sino que también se incrementa en países en desarrollo. Esa baja se 
debe a una combinación de factores sociales tales como la urbanización y el aumento de las demandas recaídas en las mujeres hacia prácticas y políticas sobre el cuidado de la salud, y a las estrategias del mercado para formular alternativas de alimentación.

Sin embargo, el conjunto abrumador de investigaciones esta en favor de la alimentación natural en lugar de sustitutos. Las Agencias internacionales responsables están haciendo llamados a los gobiernos para que garanticen que las mujeres estén autorizadas a amamantar a sus niños de cuatro a seis meses desde el nacimiento y continuar esta práctica con otros alimentos apropiados como suplemento, hasta el segundo año de vida o mas allá (3). Su reunión, por lo tanto, intenta ilustrar las bases científicas para alentar políticas sociales y condiciones de empleo que permitan a las madres hacerlo.

En términos prácticos, lo que estamos diciendo es que las madres necesitan tiempo, información y apoyo. Tanto se espera de las mujeres en muchas sociedades que el tiempo para dedicarlo al amamantamiento y cuidados tempranos no esta siempre al alcance. A diferencia de otros modos de alimentación nadie puede substituir a la madre en esta natural actividad. Igualmente, las mujeres tienen el derecho de estar informadas verazmente sobre las ventajas de esta práctica, así como también sobre las dificultades en torno a ambos casos. Los profesionales en el cuidado de la salud también deberían ser alentados y entrenados propiamente para ayudar a las mujeres en estos menesteres.

4. En la reciente Encíclica Evangelium vitae yo escribí que "una política familiar deber ser la base y fuerza que impulse todas las políticas sociales... Es incluso necesario repensar las políticas de trabajo, urbanas, residenciales y los servicios sociales para armonizar los programas de trabajo con el tiempo disponible para la familia, a fin de que se torne efectivamente posible cuidar de los niños y los mayores". (4) ¿Es esta una vaga utopía, o es la senda obligada hacia un genuino bienestar de la sociedad? Aun esta breve reflexión sobre el mismo acto individual y privado de una madre alimentando a su criatura nos lleva a un profundo y critico repensar de gran alcance sobre ciertos 
presupuestos sociales y económicos y las negativas consecuencias humanas y morales que se están volviendo mas y mas difíciles de ignorar. Ciertamente, un re-examen radical de muchos aspectos que prevalecen, como patrones socioeconómicos de trabajo, competitividad económica y falta de atención a las necesidades de la familia, se hace urgentemente necesario.

5. Estoy, por ello, muy agradecido a todos ustedes por haber ofrecido su tiempo y cooperación en esta reunión co-patrocinada por la Pontificia Academia de ciencias y la Sociedad Real. Espero la síntesis y el informe de sus hallazgos a fin de que esta información pueda circular ampliamente hacia nuestras agencias de la Iglesia e instituciones interesadas a través del mundo. Ruego por el éxito de sus investigaciones por su propio bienestar personal. Que las bendiciones de Dios os den fuerza, alegría y paz y estas estén con cada uno de ustedes y los miembros de sus familias.

\section{Referencias}

Salmos 22:9, La Biblia de Jerusalén (1966). Nueva York: Doubleday. Pío XII Alocución a las madres, octubre 6, 1941, en: Monjes de Solesmes,(Ed.). La Mujer en el Mundo Moderno. Boston: Las Hijas de San Pablo.

UNICEF (1990). Infancia y Desarrollo en los 90s. Un libro de fuentes de UNICEF. Nueva York: UNICEF

Juan Pablo II. Evangelium vitae (1995). En: Orígines 24(42), 6 abril 1995. Washington, DC: Servicio Católico de Noticias. 


\section{Discurso al Santo Padre}

En la Audiencia Solemne concedida a los participantes del Grupo de Trabajo el 12 de mayo de 1995, Su Excelencia Mons. James T. McHugh, Obispo de Camden, NJ, USA, dirigió el siguiente discurso:

Muy Santo Padre:

Me es grato presentarle a Usted a los participantes del Grupo de Trabajo sobre "Amamantamiento: Ciencia y Sociedad". La reunión de este Grupo de Trabajo es co-patrocinado por la Pontificia Academia de Ciencias y la Sociedad Real de Londres. Las personas que toman parte en esta reunión son médicos y científicos quienes están comprometidos en la investigación científica y quienes han acumulado datos muy importantes sobre las ventajas del amamantamiento tanto para la madre como para la criatura.

Existen evidencias considerables de que el amamantamiento proporciona una nutrición adecuada a los niños y que también protege a la criatura contra las amenazantes infecciones en la época temprana de vida. La madre, incluso, se beneficia al saber que ella esta proporcionando buena alimentación. Muestra también la investigación, que el amamantamiento esta asociado con la reducción del riesgo del cáncer mamario. El regreso de la ovulación se inhibe en la madre que de lleno amamanta, al menos durante los primeros seis meses después del nacimiento, con lo cual proporciona importantes beneficios a la salud familiar porque aumenta la distancia entre los nacimientos.

Estamos ahora llegando a una mejor comprensión de los componentes nutricionales de la leche humana y de la receptividad y respuesta de parte de la criatura. Los esfuerzos de nuestros participantes están dirigidos hacia la capacitación de las mujeres para iniciar y sostener el 
amamantamiento y hacer capaz a los bebés de beneficiarse de lleno. Los informes de la investigación y las discusiones entre nuestro Grupo de Trabajo son valiosas contribuciones.

Desgraciadamente, existen muchos factores que desaniman o inhiben a las mujeres de esta importante práctica. En los países desarrollados son obstáculos las demandas del paso rápido de la vida y del tiempo. La ausencia de una vida familiar estable y su sustento afectan a muchas mujeres. Los patrones de empleo, el entorno del trabajo e la ausencia de licencia de tiempo suficiente a la madre crea dificultades.

En los países en desarrollo en donde el amamantamiento ha sido una práctica muy común, la urbanización, el trabajo fuera del hogar, y otros aspectos de la modernización tienden a disminuir esta práctica. Es por ello, importante proteger y reforzar el apoyo cultural para las prácticas del amamantamiento dentro de la familiar.

Nuestro grupo de Trabajo ha reconocido, incluso, que no obstante que el amamantamiento primario compromete a la madre y la criatura, hay también un papel importante para los padres. Cada elemento del cuidado del bebé es de mutual responsabilidad y entrega de ambos padres. El padre deber ser particularmente sensible a las necesidades físicas que tiene la madre y debe asistirla para que obtenga una nutricio y descanso adecuado. El padre debe dar su aprobación y estimulo para ayudar a la madre a mantener la práctica. Toda mujer debería ser apoyada en todos los aspectos de su maternidad por su familia y por la sociedad.

Nuestro Grupo de Trabajo esta muy complacido con esta oportunidad para presentar y revisar los importantes datos investigados. Estamos agradecidos por haber podido reunirnos con ustedes. El Santo Padre, y nosotros pedimos su bendición y sus oraciones. 


\title{
AMAMANTAMIENTO Y DESARROLLO INFANTIL
}

\author{
Ernesto Pollitt ${ }^{1}$ y Patricia Kariger ${ }^{2}$ \\ Departamento de Pediatría y Programa de Nutrición Internacional, \\ Universidad de Califormia, Davis, California
}

1. Obtuvo su título de Psicólogo Profesional en la Pontificia Universidad Católica del Perú y se doctoró en la Universidad de Cornell, Ithaca, Nueva York. Ha sido profesor en las universidades de Yale (Departamento de Pediatría), Massachusetts Institute of Technology (Departamento de Nutrición), Texas (Departamentos de Nutrición y Ciencias de la Conducta) y California (Pediatría, Nutrición Internacional y Desarrollo Humano). Fue nombrado Profesor Invitado Sir Clavering Fison en 1996 en la Universidad de Londres. Asimismo trabajó por un periodo de dos años como investigador científico en el Instituto de Investigación para el Desarrollo Social de las Naciones Unidas en Ginebra, Suiza. En 1998 es nombrado Profesor Honorario del Departamento de Humanidades de la Pontificia Universidad Católica del Perú. Actualmente es consultor de varios organismos internacionales y fundaciones privadas. Reside en Davis, California. Correo electrónico: epollitt@ucdavis.edu.

2. Es Magister en psicología de la Universidad Estatal de San Diego. Se graduó como psicóloga en la Universidad de California (Irvine). Ha trabajado como profesora asistente en el Departamento de Desarrolla Humano de la Universidad de California en Davis y actualmente se desempeña como instructora. Ha participado en investigaciones en el centro para el estudio del niño y de la familia del hospital de San Diego y actualmente es asistente de investigación del Departamento de Pediatria de la Universidad de California. Dirección: 4231 Montgomery Street, Apt. 205. Oakland, California 94611. Telf: (560) 594-7455. 
Esta reseña focaliza las ventajas y desventajas que ofrece la lactancia para el desarrollo mental del niño. Los estudios se refieren a tres temas: 1) correlación entre tipo de alimentación y rendimiento en diversas pruebas de desarrollo mental antes y después de los primeros tres años de vida; 2) prevención de deficiencias de nutrimentos que afectan adversamente el desarrollo del niño y prevención de secuelas en el desarrollo en niños nacidos antes de termino y con bajo peso; y 3) contaminación de la leche de pecho por drogas y contaminantes ambientales.

Se presenta una visión sobre los efectos del amamantamiento dentro los tres temas a tratar. Nuestra evaluación indica que los estudios no permiten llegar a conclusiones definitivas, particularmente en el caso de los temas uno $y$ tres. La mejor evidencia disponible se refiere al segundo tema; sobre todo en el caso de los efectos de los ácidos grasos en el desarrollo del cerebro y aquellas provenientes de estudios longitudinales de niños que nacieron antes de termino y con muy bajo peso.

En nuestra opinión es necesario obrar con mucha cautela en la evaluación de las recomendaciones de la Organización Mundial de la Salud sobre la lactancia en aquellos casos en los que la leche de pecho puede estar contaminada por drogas o por contaminantes ambientales. Palabras claves: desarrollo infantil, desarrollo mental, lactancia.

\section{Breastfeeding and child development}

This brief review focuses on the advantages and disadvantages of human lactation for the mental development of children. The review covers theree topics: (1) Correlation between type of feeding and performance on different mental tests administered before and after the first three years of postnatal life, (2) Prevention of nutritional deficiencies that have adverse effects on cognition and prevention of sequels from pre-term births and low birth weight; (3) Contamination of human milk.

The purpose is to provide a representative view of these three topics. Our evaluation of the publised data shows that the information does not allow for definitive conclusions, particularly in reference to the first and third topic. The strongest available evidences is found on studies of the effects of free fatty acids on cerebral growth and on longitudinal studies of pre-term children of low birth weight.

In our impression it is necessary to evaluate carefully the recommendation of the World Health Organization regarding the benefits of lactation in those cases when drugs or enviromental minerals and chemicals have contaminated human milk.

Keywords: child development, mental development, lactation. 


\section{Introducción}

La hipótesis sobre los beneficios del amamantamiento en el desarrollo mental del niño se apoya en consideraciones teóricas e investigaciones que encajan en la literatura sobre la psicobiología del desarrollo. En este artículo evaluamos críticamente la información contemporánea que nos ha sido disponible sobre el tema. Nuestro objetivo es presentar una revisión bibliográfica que ofrezca una imagen representativa pero no exhaustiva. Inclusive en algunos aspectos del tema identificamos el problema, pero no podemos citar datos porque no los hay. No hacemos referencia a otros efectos benéficos del amamantamiento que ya han sido establecidos, por ejemplo, en la fertilidad de las mujeres (McNeilley, 1996) y en la resistencia a las infecciones del niño (Howie, 1996).

Los estudios sobre los efectos del amamantamiento en el desarrollo mental del niño han tenido tres objetivos principales. El primero ha sido la determinación de la diferencia en el rendimiento intelectual de niños que habían sido amamantados y niños que habían sido alimentados con fórmulas lácteas o con leche de vaca. Un segundo objetivo ha sido evaluar si la leche de pecho actúa como factor preventivo primario y secundario. El análisis de la contaminación de la leche de pecho y su impacto en el desarrollo del niño define el tercer objetivo. Estos tres objetivos los hemos usado para clasificar la información a discutir y los presentamos a continuación en forma de hipótesis.

En las secciones que siguen definimos amamantar y lactación como dar de mamar y amamantamiento como la acción y efecto de amamantar. Lactar es también dar de mamar y lo usamos como sinónimo de amamantar. Leche de pecho es la leche extraída da la mama por la succión del bebé o 
por otros medios. El término biberón lo reservamos para la alimentación del niño con una fórmula láctea o con leche de vaca.

\section{A. El niño amamantado durante los primeros meses de vida tiene un desarrollo intelectual ${ }^{1}$ más rápido que el de los niños alimentados con fórmulas lácteas comerciales o con leche de vaca}

Esta sección divide la información de acuerdo a la edad de los niños al momento de ser evaluados para determinar el efecto del amamantamiento. En el primer grupo las edades de los niños fluctuaban entre los 6 y los 36 meses. Las mediciones del desarrollo mental generalmente se hicieron con la Escala de Desarrollo Mental y Motor de Nancy Bayley. Los estudios que constituyen el segundo grupo evaluaron a niños entre 3 y 15 años de edad. En estos casos los autores utilizaron tests que generan un cociente intelectual (CI) como el test de Wechsler u otras pruebas que miden aspectos particulares de la inteligencia.

\section{A.1. Efectos hasta el tercer año (cuadro 1)}

Este grupo incluye cinco estudios (Florey, Leech y Blackhall, 1995; Morrow-Tlucak, Haude y Ernhart, 1988; Temboury, Otero, Polanco y Arribás, 1994; Young, Buckley, Hamza y Mandarano, 1982) que compararon el desarrollo mental de niños que fueron amamantados y niños que recibieron fórmulas lácteas en biberón. El estudio de Rogan y Gladen

1 Para la formación de estas hipótesis usamos el término "desarrollo intelectual" e incluimos dentro de este las mediciones generadas por las pruebas de desarrollo mental (ej. Bayley) durante los dos primeros años de vida y los resultados de los tests de inteligencia (ej. Wechsler) administrados posteriormente. La descripción de la diferencia entre estas medidas y su relación con la edad de los niños va más allá de los propósitos de este trabajo. El lector debe estar consciente sin embargo que dentro de los mismos sujetos las correlaciones entre los resultados de la escalas de desarrollo y los resultados de las pruebas de inteligencia son modestas. Estas correlaciones aumentan positivamente con la edad de los niños en la primera evaluación y negativamente con el tiempo entre la primera y la segunda evaluación. 


\section{Cuadro 1}

Estudios sobre el Efecto del Amamantamiento en el Desarrollo de Bebés (0 a 12 meses) y de Niños Pequeños

\begin{tabular}{|c|c|c|c|c|c|}
\hline Istudio & Diseño del estridio & Muestra & $\begin{array}{l}\text { Criterios de } \\
\text { exclustón }\end{array}$ & $\begin{array}{l}\text { Resultado de } \\
\text { las variables }\end{array}$ & $\begin{array}{l}\text { Resultados } \\
\text { significattvos }\end{array}$ \\
\hline $\begin{array}{l}\text { Temboury } \\
\text { y otros, } \\
1994\end{array}$ & $\begin{array}{l}\text { Estudio de correlación, } \\
\text { longitudinal y prospec- } \\
\text { tivo. Desarrollo mental } \\
\text { medido entre } 18 \text { y } 29 \\
\text { meses. } \\
\text { Los datos de los antece- } \\
\text { dentes variables recolec- } \\
\text { tados cuando el sujeto } \\
\text { era sometido a prueba. } \\
\text { Sujetos clasificados se- } \\
\text { gún el método de ali- } \\
\text { mentación; biberón: } \\
\text { amamantados } \leq 1 \text { me- } \\
\text { ses }(n=99) ; \text { pecho: ama- } \\
\text { mantados } \geq 3 \text { meses } \\
(n=130) \text {. }\end{array}$ & $\begin{array}{l}229 \text { recién nacidos } \\
\text { en hospitales de } \\
\text { Madrid; clase social } \\
\text { media y baja. }\end{array}$ & $\begin{array}{l}\text { Edad de gestación } \\
<36 \text { sem. Peso al } \\
\text { nacer < } 2400 \mathrm{~g} \text {. } \\
\text { Complicaciones } \\
\text { perinatales; anoma- } \\
\text { lías mayores al na- } \\
\text { cer; pobre puntaje } \\
\text { Apgar } 5 \text { min.; ama- } \\
\text { mantado durante } 2 \\
\text { meses. Prueba de } \\
\text { seguimiento in- } \\
\text { completa. }\end{array}$ & $\begin{array}{l}\text { Puntajes IDM e } \\
\text { IDP de Bayley a } \\
\text { los } 18-29 \text { meses. } \\
\text { Covariables: edu- } \\
\text { cación materna, } \\
\text { edad, condición de } \\
\text { trabajo, clase social, } \\
N^{\circ} \text { de hermanos; } \\
\text { riesgo psicosocial; } \\
\text { controladores tam- } \\
\text { bién codificados } \\
\text { por timidez, pata- } \\
\text { letas temperamen- } \\
\text { tales, hiperactivi- } \\
\text { dad. }\end{array}$ & $\begin{array}{lll}\begin{array}{l}\text { Bajos puntajes IDM a } \\
\text { los } 18-29 \text { meses predi- } \\
\text { chos por: }\end{array} & \\
\begin{array}{l}\text { alimentados } \\
\text { con biberón }\end{array} & 1.86 & .044 \\
\begin{array}{l}\text { baja educa- } \\
\text { ción materna }\end{array} & 2.90 & .012 \\
\begin{array}{l}N^{\circ} \text { de } \\
\text { hermanos }\end{array} & 2.63 & .002 \\
\text { pataletas } & 2.38 & .016\end{array}$ \\
\hline $\begin{array}{l}\text { Rogan y } \\
\text { Gladen, } \\
1993\end{array}$ & $\begin{array}{l}\text { Estudio perspectivo, } \\
\text { longitudinal, de correla- } \\
\text { ción. Entrevistas a madres } \\
\text { sobre los métodos de } \\
\text { alimentación desde el na- } \\
\text { cimiento hasta los } 5 \text { años. } \\
\text { Medidas de desarrollo }\end{array}$ & $\begin{array}{l}600+\text { bebés de } \\
\text { término completo, } \\
\text { mayormente blan- } \\
\text { cos. Clase social } \\
\text { mediana; familias } \\
\text { bien educadas de } \\
\text { Carolina del Nor- } \\
\text { te, USA. }\end{array}$ & $\begin{array}{l}\text { Madres que no in- } \\
\text { tentaron amaman- } \\
\text { tar o faltas de inte- } \\
\text { rés en estar en el es- } \\
\text { tudio de largo pla- } \\
\text { zo. }\end{array}$ & $\left|\begin{array}{l}\text { Puntajes IDM e } \\
\text { IDP de Bayley a los } \\
6,12,18 \text { y } 24 \\
\text { meses. Factores de } \\
\text { confusión: edad } \\
\text { materna, raza, ocu- } \\
\text { pación, educación, }\end{array}\right|$ & $\begin{array}{l}\text { Diferencias promedio a } \\
\text { los } 24 \text { meses; muy largo } \\
\text { v. corto: }+6.7 \text { puntos } \\
\text { IDM. Muy largo v. ali- } \\
\text { mentado con biberón: } \\
+5.6 \text { puntos IDM; +5.9 } \\
\text { puntos IDP. También }\end{array}$ \\
\hline
\end{tabular}




\begin{tabular}{|c|c|c|c|c|c|}
\hline Estudito & Diseño del estudio & Muestra & $\begin{array}{l}\text { Criterios de } \\
\text { exclasion }\end{array}$ & $\begin{array}{l}\text { Resultado de } \\
\text { las variables }\end{array}$ & $\begin{array}{l}\text { Resultados: } \\
\text { significativos }\end{array}$ \\
\hline & 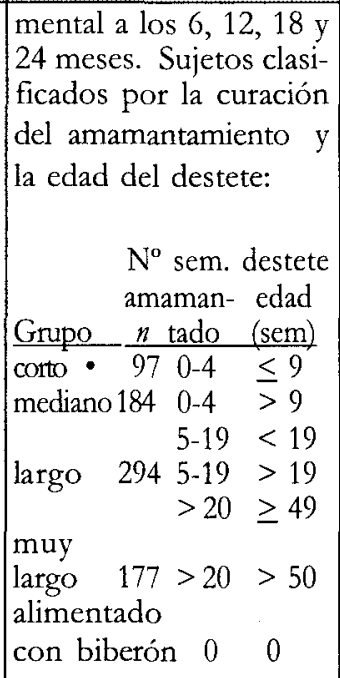 & & & $\begin{array}{l}\text { fumar y beber du- } \\
\text { rante el embarazo, } \\
\text { sexo del bebé, peso } \\
\text { al nacer, orden de } \\
\text { nacimiento. }\end{array}$ & $\begin{array}{l}\text { se encontraron efectos } \\
\text { positivos por edad ma- } \\
\text { terna y orden de naci- } \\
\text { miento. }\end{array}$ \\
\hline $\begin{array}{l}\text { Florey } \\
\text { et al., } \\
1995\end{array}$ & $\begin{array}{l}\text { Estudio del seguimien- } \\
\text { to correlativo examinan- } \\
\text { do la influencia de los } \\
\text { métodos alimenticios o } \\
\text { de desartollo motor y } \\
\text { mental a los } 18 \text { meses. }\end{array}$ & $\begin{array}{l}\text { Muestra basada en } \\
\text { una población de } \\
846 \text { primogénitos } \\
\text { únicos enviados a } \\
\text { un hospital en } \\
\text { Dundee, Escocia. }\end{array}$ & & $\begin{array}{l}\text { Puntajes del IDM } \\
\text { e IDP de Bayley a } \\
\text { los } 18 \text { meses. }\end{array}$ & $\begin{array}{l}\text { Puntajes promedio IDM: } \\
\text { amamantados, } 110.2 ; \text { ali- } \\
\text { mentados con biberón, } \\
\text { 102.5. No se halló dife- } \\
\text { rencias promedio de gru- } \\
\text { po en los puntajes IDP. }\end{array}$ \\
\hline
\end{tabular}




\begin{tabular}{|c|c|c|c|c|c|}
\hline 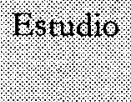 & I Dischio del estudio & Muestra? & $\begin{array}{l}\text { Criterios de } \\
\text { exclustón: }\end{array}$ & $\begin{array}{l}\text { Ressultado de } \\
\text { las vartables }\end{array}$ & $\begin{array}{l}\text { Resultados } \\
\text { significativas }\end{array}$ \\
\hline & $\begin{array}{l}\text { Los datos sobre alimen- } \\
\text { tación obtenidos de fi- } \\
\text { chas de hospital y de re- } \\
\text { gistros de las visitas de } \\
\text { enfermeras en los hoga- } \\
\text { res en los } 2 \text { primeros } \\
\text { meses. Los IDM e IDP } \\
\text { de Bayley se administra- } \\
\text { ron a } 582 \text { niños a los } 18 \\
\text { meses. Sujetos clasifica- } \\
\text { dos por métodos ali- } \\
\text { menticios: amamantados } \\
(n=228) \text {; alimentados } \\
\text { con biberón }(n=354) \text {. }\end{array}$ & & & & \\
\hline
\end{tabular}

Nota. IDM: Indice de Desarrollo Mental. IDP: Indice de Desarrollo Psicomotor. 
(1993) también incluyó evaluaciones con las Escalas de McCarthy desde los tres, hasta los cinco años de edad, y por eso decidimos incluirlo en esta y en la siguiente sección.

La definición de la variable independiente (lactar) varía entre los cinco estudios y por eso no es posible hacer un meta-análisis con el fin de llegar a conclusiones definitivas. Esa variabilidad se puede ver en la duración de amamantamiento; en los nutrimentos de las fórmulas administradas a los niños con biberón; y en la naturaleza y número de los factores que pudieron confundir la relación entre la alimentación y el desarrollo. Nuestras generalizaciones se remiten a impresiones cuantitativas.

Ninguno de los cinco estudios encontró beneficios del lactar en el desarrollo mental durante los primeros 11 meses de vida. Las primeras diferencias estadísticamente significativas concordantes con la hipótesis se observaron a los 12 meses o después. Por ejemplo, en el estudio de Morrow-Tlucak et al. (1988), se encontró que a los 12 meses el promedio del Indice de Desarrollo Mental (IDM) de los bebés alimentados exclusivamente con biberón fue 10 puntos menor al IDM de los bebés que fueron amamantados por lo menos durante cuatro meses (cuadro 3). En términos generales, esta diferencia de 10 puntos puede considerarse como una diferencia biológica importante en el desarrollo mental temprano, ya que es equivalente a 0.60 de una desviación estándar del Bayley.

Después de los primeros 12 meses de vida el IDM promedio de los bebés alimentados con biberón fue sistemáticamente más bajo que el de los niños amamantados. Las diferencias inter-grupales variaron de 3.5 (Young et al., 1982) a 13.9 (Morrow-Tlucak et al., 1988) puntos del IDM.

Por otros estudios (Pollitt y Oh, 1994) sabemos que las escalas del desarrollo mental como la Escala de Bayley que se usan para evaluar a los niños menores a los 12 meses generalmente carecen de sensibilidad para detectar beneficios sutiles producidos por intervenciones experimentales con energía y proteína o con micronutrientes en el desarrollo mental. Esta limitación en el método de medición podría explicar porque los efectos de amamantamiento se observaron solo a partir de los 12 meses 
de edad o después. Por ello solo podemos llegar a una conclusión conservadora: el repertorio conductual después del primer año de vida es mas amplio en el bebé que fue amamantado que en aquel que fue alimentado con biberón.

\section{A.2. Efectos después de los tres años (cuadro 2)}

Además de un estudio publicado en 1929 (Hoefer y Hardy), encontramos tres estudios (Fergusson, Beautrais, Silva 1982; Rodgers, 1978; Rogan y Gladen, 1993) que sugieren que los niños que reciben leche de pecho tienen una ventaja en pruebas de inteligencia y de aprovechamiento escolar administrados de 5 a 15 años de edad. Sin embargo, como se vio en los estudios de bebés ya presentados, los estudios con niños mayores tampoco constituyen un grupo homogéneo. Hay diferencias de importancia biológica entre las edades de los niños al momento del examen con las pruebas administradas, y en el número y naturaleza de los factores de confusión que fueron considerados relevantes. Por ejemplo, en un estudio (Rogan y Gladen, 1993) la última evaluación se llevó a cabo a los 5 años de edad, y en otro (Rodgers, 1978) los sujetos fueron examinados hasta los 15 años. Las pruebas para evaluar el funcionamiento intelectual también fueron diferentes. Por ejemplo, Rogan y Gladen (1993) usaron la escala de McCarthy para la evaluación de preescolares, mientras Fergusson et al. (1982) usaron la prueba de Imagen y Vocabulario de Peabody para preescolares; la escala de Stanford-Binet para los de cinco años de edad; y la escala de Wechsler para los de siete años de edad. Rodgers (1978) usó una prueba de inteligencia de imágenes y pruebas de habilidades cognitivảs específicas (ej. matemáticas).

Los estudios generalmente incluyen muestras comparativamente grandes que van de 383 (Hoefer y Hardy, 1929) a más de 5,000 sujetos (Rodgers, 1978). El tamaño de estas muestras permitió que aun cuando las diferencias numéricas entre grupos fueran relativamente estrechas se pudieran encontrar diferencias estadísticamente significativas. La importancia de esta observación está en que el significado estadístico no garantiza importancia psicobiológica. Pero esta nota de cautela también debe verse 
en relación a la consistencia de los hallazgos entre todos los estudios. Los resultados forman un patrón. Todos los estudios en niños mayores a los 11 meses observaron que los niños que fueron amamantados tuvieran un desarrollo intelectual mas acelerado que aquellos que fueron alimentados con biberón.

\section{A.3. Discusión}

Entre otros, hay dos aspectos saltantes en los estudios que hemos revisado. Por un lado la debilidad de los diseños de investigación y por el otro, es la consistencia en los resultados. Diseños basados en correlaciones no permiten, por definición, controlar todas las variables que pueden confundir las relaciones entre la variable independiente (X: presencia o ausencia de amamantamiento) y la dependiente ( $\mathrm{Y}$ : desarrollo). Esta falta de control puede llevar a conclusiones falsas al atribuir la variación en $\mathrm{Y}$ a la variable $\mathrm{X}$ cuando se le debe atribuir a $\mathrm{Z}$. Por ejemplo, una mayor dedicación al bebé de las madres que lactan podría ser, hipotéticamente, el determinante principal de las ventajas comparativas que le son atribuidas a la leche de pecho. El diseño puede también impedir la visión de una interacción entre la variable $\mathrm{X}$ y otra variable $(\mathrm{Z})$, lo cual puede llevar equivocadamente a la conclusión de un efecto principal en $\mathrm{Y}$. Por ejemplo, la ventaja comparativa en $\mathrm{Y}$ podría ser explicada por la interacción $(\mathrm{X}-\mathrm{Z})$ entre la dedicación al bebé $(\mathrm{Z})$ y el lactar $(\mathrm{X})$ y no por un efecto principal de X. Hipotéticamente esta interacción estaría operando de tal forma que el lactar solo beneficia a algunos niños: aquellos cuyas madres les prestan una dedicación especial.

En conclusión, los defectos en el diseño han impedido probar la primera de las tres hipótesis que presentamos. Sin embargo, la consistencia en los resultados a la cual ya nos hemos referido refuerza el mérito científico de la hipótesis. Investigaciones futuras deberán estar, en nuestra opinión, enraizadas en premisas contemporáneas básicas del desarrollo humano que subrayan la influencia de las interacciones entre los determinantes del desarrollo. 


\section{Cuadro 2}

Estudios sobre el Efecto del Amamantamiento en el Desarrollo Mental de Niños

\begin{tabular}{|c|c|c|c|c|c|}
\hline I. Estuidio & Diserio del estudio & Mrestrat: & $\begin{array}{l}\text { Criterios dé } \\
\text { exclusion }\end{array}$ & $\begin{array}{l}\text { Restitadio de } \\
\text { I. las variabless }\end{array}$ & $\begin{array}{l}\text { Resultados } \\
\text { significativos }\end{array}$ \\
\hline $\begin{array}{l}\text { Hoefer y } \\
\text { Hardy, } \\
1929\end{array}$ & $\begin{array}{l}\text { Estudio de correlación, } \\
\text { longitudinal, y prospec- } \\
\text { tivo del crecimiento. } \\
\text { Sujetos clasificados por } \\
\text { la duración del amaman- } \\
\text { tamiento exclusivo ali- } \\
\text { mentado artificialmente } \\
(n=38) ; \\
\leq 3 \text { meses }(n=78) ; \\
4-9 \text { meses }(n=77) ; \\
10-20 \text { meses }(n=190)\end{array}$ & $\begin{array}{l}383 \text { niños de } 7 \text { a } \\
13 \text { años. }\end{array}$ & $\begin{array}{l}\text { No se reportan da- } \\
\text { tos sobre alimenta- } \\
\text { ción. }\end{array}$ & 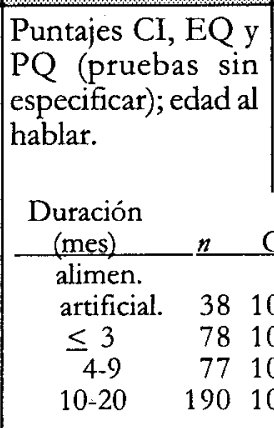 & 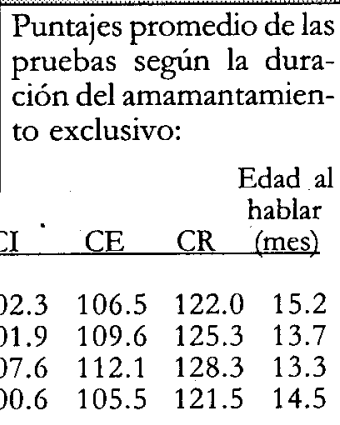 \\
\hline $\begin{array}{l}\text { Rogan / } \\
\text { Gladen, } \\
1993\end{array}$ & $\begin{array}{l}\text { Seguimiento del estudio } \\
\text { descrito en el cuadro } 1 ; \\
\text { desarrollo mental medi- } \\
\text { do a los } 3,4 \text { y } 5 \text { años. }\end{array}$ & & Ver cuadro 1 & $\begin{array}{l}\text { Puntajes de Escala } \\
\text { de McCarthy a los } \\
3,4 \text { y } 5 \text { años. } \\
\text { Tarjeta de informe } \\
\text { de 3er. grado. No- } \\
\text { tas en inglés y ma- } \\
\text { temáticas. }\end{array}$ & $\begin{array}{l}\text { Resultados de todas las } \\
\text { escalas mostrando una } \\
\text { tendencia a puntajes altos } \\
\text { en grupos de amamanta- } \\
\text { miento en toda edad. } \\
\text { Ventajas de puntajes pro- } \\
\text { medio que van de }+2.8 \text { a } \\
+4.8 \text { puntos para un } \\
\text { amamantamiento muy } \\
\text { largo vs uno corto o ali- } \\
\text { mentados con biberón. }\end{array}$ \\
\hline
\end{tabular}




\begin{tabular}{|c|c|c|c|c|c|}
\hline Estuaio. & Diseño det estudio & Wuestrat & exclision. & $\begin{array}{l}\text { Resultado de } \\
\text { has ratiables? }\end{array}$ & 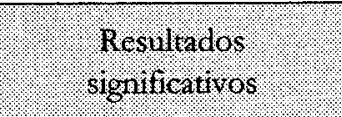 \\
\hline & & & & & $\begin{array}{l}\text { Las tarjetas no informa- } \\
\text { ron de diferencias signifi- } \\
\text { cativas entre los grupos de } \\
\text { 3er. grado. }\end{array}$ \\
\hline \multirow[t]{2}{*}{$\begin{array}{l}\text { Fergusson } \\
\text { et al., } \\
1982\end{array}$} & \multirow{2}{*}{$\begin{array}{l}\text { Estudio de seguimien- } \\
\text { to de correlación, longi- } \\
\text { tudinal y prospectivo. } \\
\text { Desarrollo mental medi- } \\
\text { do a los } 3,5 \text { y } 7 \text { años. } \\
\text { Sujetos clasificados por } \\
\text { meses de amamanta- } \\
\text { miento: alimentados } \\
\text { con biberón ( } 0 \text { meses); } \\
\text { amamantados < } 4 \text { me- } \\
\text { ses; amamantados } \\
>4 \text { meses }\end{array}$} & \multirow[t]{2}{*}{$\begin{array}{l}\text { Cohorte de naci- } \\
\text { mientos de niños } \\
\text { participantes en un } \\
\text { estudio sobre de- } \\
\text { sarrollo en Nue- } \\
\text { va Zelandia. }\end{array}$} & $\begin{array}{l}\text { Datos faltan sobre } \\
\text { el método de ali- } \\
\text { mentación. }\end{array}$ & $\begin{array}{l}\text { Puntajes en la prue- } \\
\text { ba de CI: Edad } 3 \\
\text { años, prueba de } \\
\text { imágenes y vocabu- } \\
\text { lario de Peabody; } \\
\text { edad de } 5 \text { años, } \\
\text { Stanford-Binet; } \\
\text { edad de } 7 \text { años, CI } \\
\text { de Weschler. }\end{array}$ & \multirow[t]{2}{*}{$\begin{array}{l}\text { Promedio de ventajas } \\
\text { para el grupo amaman- } \\
\text { tados v. alimentados con } \\
\text { biberón en pruebas de } \\
\text { CI y de CL, controlados } \\
\text { por factores de confu- } \\
\text { sión: }\end{array}$} \\
\hline & & & \multicolumn{2}{|c|}{$\begin{array}{l}\text { Puntajes en la prueba de CL: edad de } \\
3 \text { y } 5 \text { años, Escalas de Desarrollo del } \\
\text { Lenguaje de Reynell; edad de } 7 \text { años, } \\
\text { prueba de habilidades psicolinguísticas } \\
\text { de Illinois. } \\
\text { Factores de confusión: inteligencia ma- } \\
\text { terna, educación y conocimientos en } \\
\text { crianza infantil, SSE; edad de gestación } \\
\text { de los niños y peso al nacer. }\end{array}$} & \\
\hline
\end{tabular}




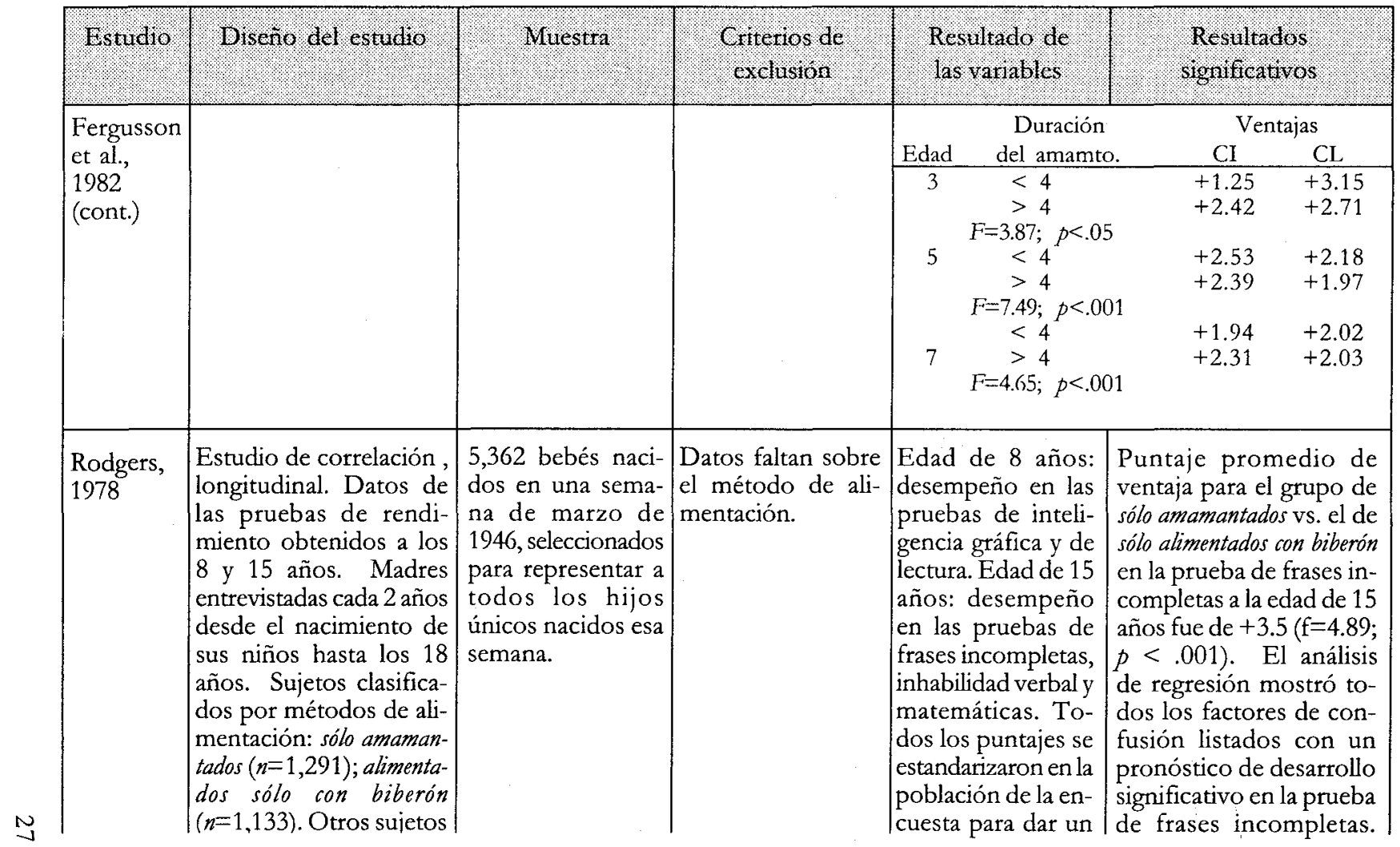




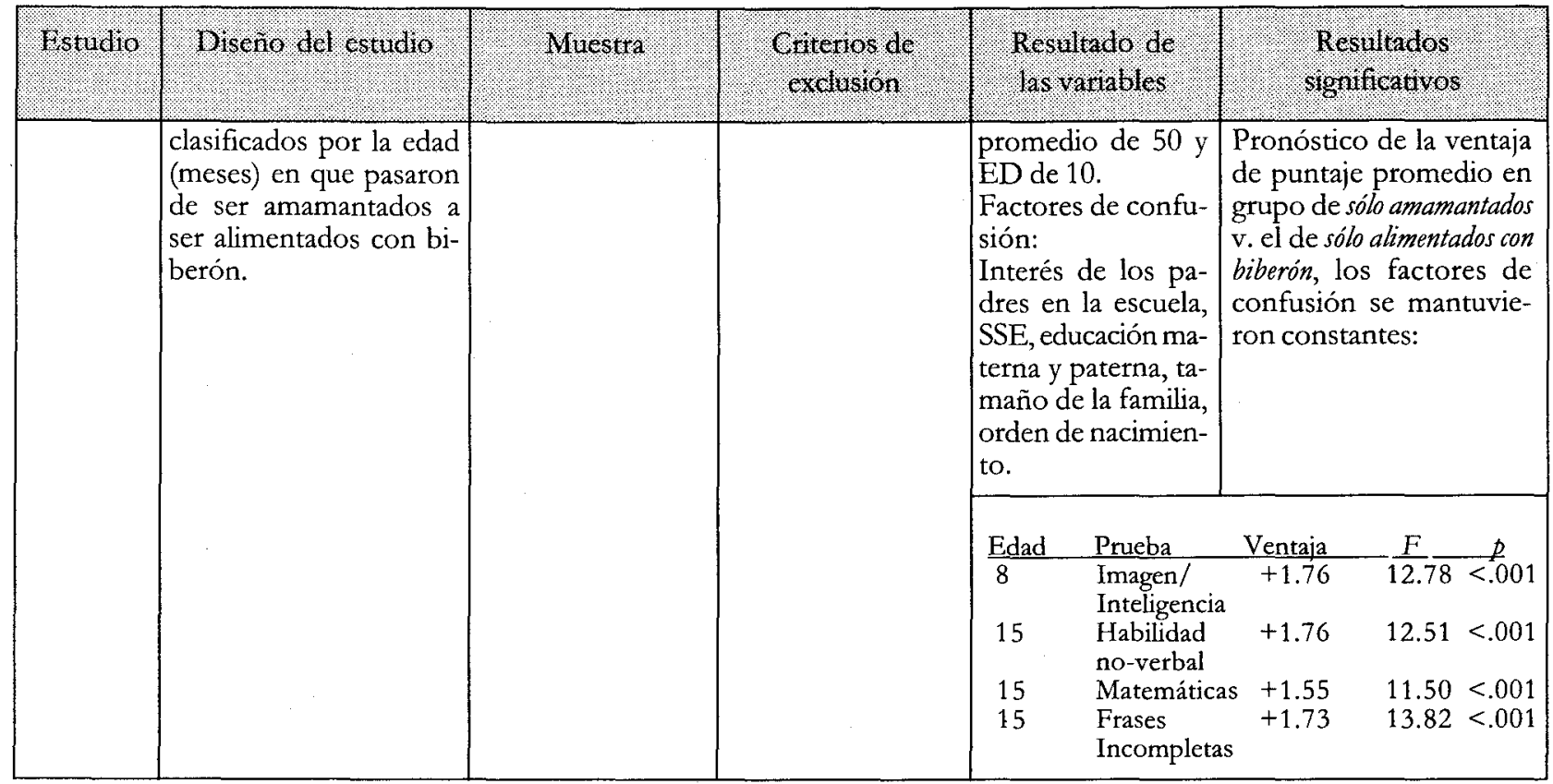

Nota. CE: Cociente Educativo. CI: Cociente Inteligencia. CL: Comprensión del Lenguaje. CD: Cociente de Desempeño. SSE: Situación socioeconómica. 
B. E1 amamantamiento previene deficiencias de nutrimentos que demoran el desarrollo intelectual; y previenen secuelas en el desarrollo intelectual de niños que nacen antes de los 37 meses de gestación y con un peso menor a los 2,500 gramos.

Los efectos preventivos del amamantamiento pueden dividirse en efectos primarios y secundarios. La prevención primaria se refiere al efecto del amamantamiento en evitar la deficiencia de nutrimentos que puede tener efectos adversos en el desarrollo mental. Efectos secundarios se presentan cuando ya existe un riesgo orgánico (ej. nacer antes de término) y el amamantamiento previene una secuela.

\section{B.1. Prevención Primaria (cuadro 3)}

Este tipo de efecto se observa en el caso de la anemia por deficiencia de hierro ${ }^{2}$. En los niños la deficiencia férrica está asociada con un retardo en el desarrollo mental y motor de los bebés (Pollitt, 1993). Además, si bien es cierto que hay diferencias entre los resultados de varios estudios, algunos estudios experimentales han demostrado que los atrasos en el desarrollo en bebés con anemia ferropénica son reversibles tres meses después de comenzar la terapia de repleción de hierro (Idjradinata y Pollitt, 1993).

El hierro en la leche de pecho es de baja concentración pero es altamente biodisponible. Esto explica porque durante los primeros seis meses de vida los bebés amamantados tienen menos probabilidades de volverse hierro deficientes y anémicos que los bebés alimentados con biberón. Esta diferencia es particularmente acentuada cuando se comparan

2. La deficiencia de hierro no es necesaria ni suficiente para producir anemia. Esta puede ser producida por la deficiencia de otros nutrimentos (ej. ácido fólico) y por factores genéticos. Además, la deficiencia de hierro puede ser leve o moderada sin producir cambios hematológicos. 
los niños que han sido amamantados y niños que reciben leche de vaca (Lonnerdal, 1982). Así, si la leche de pecho previene la anemia, también previene los atrasos del desarrollo asociados a ella. Este efecto de prevención es particularmente importante para los niños con bajo peso al nacer que son los que más riesgo tienen de volverse anémicos (Institute of Medicine, 1990).

El efecto preventivo de la leche de pecho se vio indirectamente en un experimento controlado que se limitó a medir el efecto de fórmulas lácteas fortificadas con hierro (Moffatt, Longstaffe, Beant y Dureski, 1994) (cuadro 3) . Dos grupos de bebés de dos meses de edad fueron asignados al azar para recibir Enfalac con $12.8 \mathrm{mg}$ o con $1.1 \mathrm{mg}$ de hierro elemental por litro. A los 6, 9, 12 y 15 meses de edad todos los niños fueron evaluados con la Escala Mental y Motora de Bayley. A los 9 y 12 meses se observaron que los bebés que recibieron el Enfalac con $12.8 \mathrm{mg}$ de hierro tenían un desarrollo psicomotor más acelerado que aquellos que recibieron Enfalac con $1.1 \mathrm{mg}$ de hierro. Sin embargo, no se observó diferencias en el IDM; pero ello no nos sorprende ya que, como se ha dicho, el IDM generalmente no detecta efectos asociados a variaciones en nutrimentos durante los primeros 11 meses de edad. El estudio de Moffatt es relevante a la hipótesis que nos concierne porque el Enfalac con $12.8 \mathrm{mg}$ de hierro tuvo el mismo efecto de prevención de anemia que tiene la leche de pecho. Pero es necesario precisar que, en el caso de la leche de pecho, el efecto preventivo se pierde después de los seis meses de edad (Cohen, Landa Rivera, Lonnerdal, Brown y Dewey, 1993).

\section{B.1.1. Discusión}

La prevención primaria que le hemos atribuido al amamantamiento no se basa en un cuerpo de información sólido ya que los datos que se necesitan para tomar una decisión sobre este tópico todavía no existen dentro de una sola investigación. Los datos que existen son partes relacionadas provenientes de estudios diferentes. Por un lado se cuenta con información sobre la prevención de la anemia ferropénica mediante el amamantamiento y, por otro lado, se tienen los datos sobre las limitaciones 


\section{Cuadro 3}

Estudios sobre los Efectos Preventivos Primarios

\begin{tabular}{|c|c|c|c|c|c|}
\hline Frstudio & Diseño del estadio & Muestra & $\begin{array}{l}\text { Chinerios de } \\
\text { exclasion }\end{array}$ & $\begin{array}{l}\text { Resultado de } \\
\text { las variables }\end{array}$ & $\begin{array}{l}\text { Resultados. } \\
\text { significativos. }\end{array}$ \\
\hline $\begin{array}{l}\text { Moffatt } \\
\text { et al., } \\
1994\end{array}$ & $\begin{array}{l}\text { Ensayo clínico al azar } \\
\text { longitudinal y prospecti- } \\
\text { vo comparando los efec- } \\
\text { tos de la fórmula forti- } \\
\text { ficada con hierro y la } \\
\text { normal en el desarrollo } \\
\text { mental y motor de los } \\
\text { bebés. } 112 \text { individuos } \\
\text { recibieron la fórmula } \\
\text { fortificada con hierro y } \\
113 \text { la normal durante } \\
15 \text { meses. Desarrollo } \\
\text { mental y motor medido } \\
\text { a los } 6,9,12 \text { y } 15 \text { meses. }\end{array}$ & $\begin{array}{l}225 \text { bebés alimen- } \\
\text { tados con biberón } \\
\text { de } 0-2 \text { meses. Na- } \\
\text { cidos en hospitales } \\
\text { del área de Winni- } \\
\text { peg, Canada. }\end{array}$ & & $\begin{array}{l}\text { Puntajes del IDM } \\
\text { e IDP de Bayley a } \\
\text { los } 6,9,12 \text { y } 15 \\
\text { meses }\end{array}$ & $\begin{array}{l}\text { No hubo diferencias sig- } \\
\text { nificativas entre grupos } \\
\text { en los puntajes del IDM. } \\
\text { Puntaje promedio de } \\
\text { ventaja para el grupo de } \\
\text { la fórmula fortificada con } \\
\text { bierro vs el de la fórmula } \\
\text { normal en los puntajes } \\
\text { del IDP: } \\
\begin{array}{lr}\text { Edad } & \\
\text { (meses) } & \text { Ventaja } \\
6 & +0.6 \\
9 & +4.0 \\
12 & +6.3 \\
15 & +2.8 \\
(p=.02 & \text { grupo por } \\
\text { tiempo de interacción) }\end{array}\end{array}$ \\
\hline $\begin{array}{l}\text { Agostini } \\
\text { et al., } \\
1995\end{array}$ & $\begin{array}{l}\text { Estudio prospectivo } \\
\text { casi-experimental para } \\
\text { comparar el efecto de } \\
\text { leche de pecho, fórmula } \\
\text { enriquecida con LC-AGP }\end{array}$ & $\begin{array}{l}90 \text { bebés nacidos } \\
\text { en una clínica de } \\
\text { Milan, Italia, du- } \\
\text { rante } 1 \text { año. Clasi- } \\
\text { ficación de sujetos: }\end{array}$ & $\begin{array}{l}\text { Edad de gestación } \\
<37 \text { sem. dos Pun- } \\
\text { taje Apgar }<7 \text {. Al- } \\
\text { guna enfermedad o } \\
\text { desorden perinatal. }\end{array}$ & $\begin{array}{l}\text { Puntajes en la prue- } \\
\text { ba psicomotora de } \\
\text { Brunet-Lezine que } \\
\text { evalúa la función } \\
\text { motor gruesa y }\end{array}$ & $\begin{array}{l}\text { Puntajes de Brunet-Le- } \\
\text { zine significativamente } \\
\text { más altos en los grupos } \\
\text { exclusivamente amamanta- } \\
\text { das y en los de formula }\end{array}$ \\
\hline
\end{tabular}




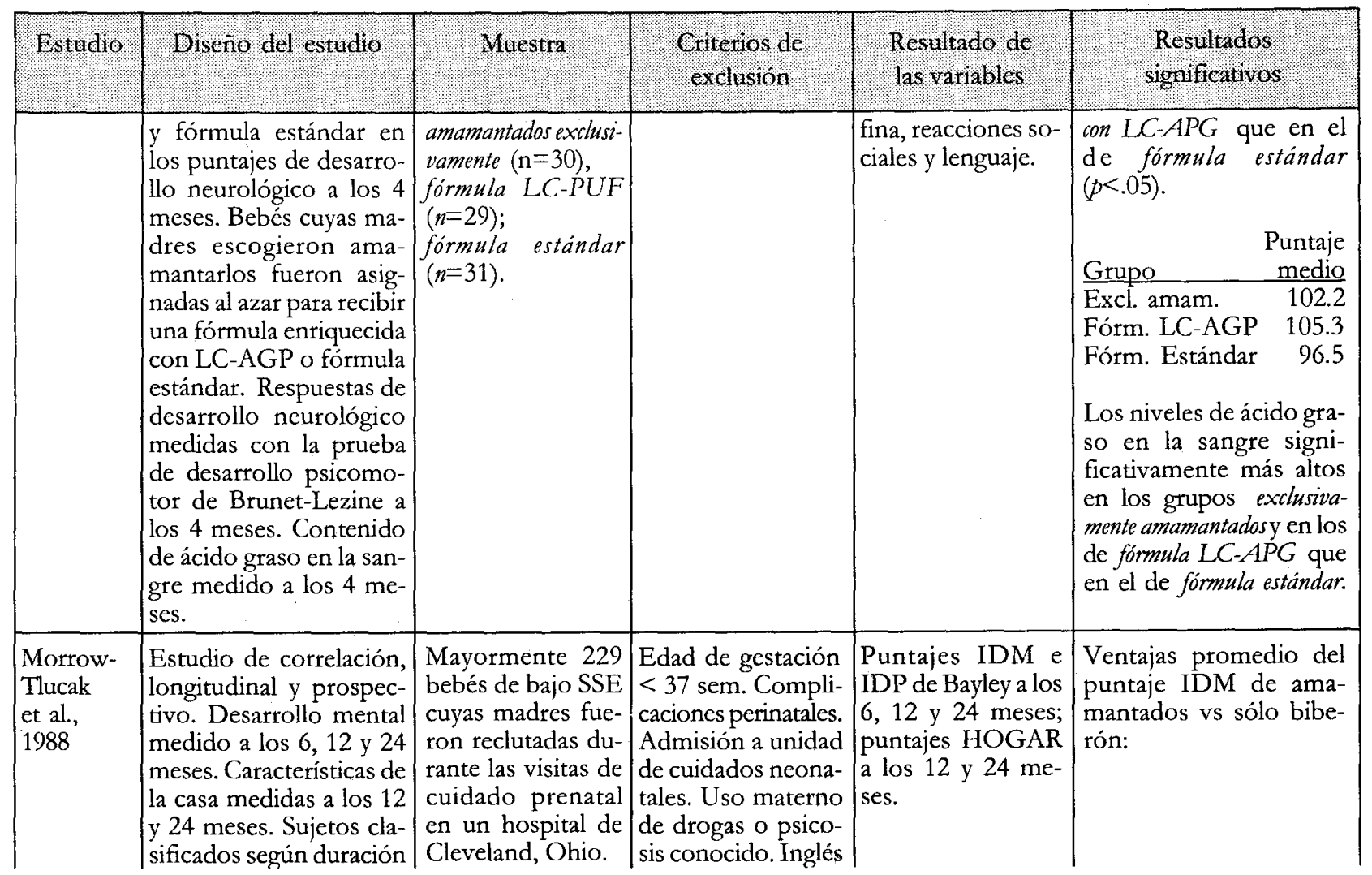




\begin{tabular}{|c|c|c|c|c|c|}
\hline Estudio & Diseño del estudio & Muestra & $\begin{array}{l}\text { Critetios de } \\
\text { exclusión }\end{array}$ & $\begin{array}{l}\text { Resultado de } \\
\text { las variables }\end{array}$ & $\begin{array}{l}\text { Resultados } \\
\text { signaificativos }\end{array}$ \\
\hline & $\begin{array}{l}\text { del amamantamiento: } \\
\text { sólo biberón }(n=157) ; \\
\text { pecbo } \leq 4 \text { meses }(n=39) \\
\text { pecbo }>4 \text { meses }(n=23) \text {. }\end{array}$ & & $\begin{array}{l}\text { no como lengua } \\
\text { primaria. Bebé } \\
\text { puesto en adop- } \\
\text { ción. Envío y reco- } \\
\text { jo en fines de se- } \\
\text { mana. Intento de la } \\
\text { familia de mudarse } \\
\text { del área. }\end{array}$ & $\begin{array}{l}\text { Factores de confu- } \\
\text { sión: raza, educa- } \\
\text { ción paterna, inteli- } \\
\text { gencia materna, uso } \\
\text { de cigarrillos, acti- } \\
\text { tud disciplinaria } \\
\text { materna. }\end{array}$ & \begin{tabular}{|l}
$\begin{array}{l}\text { Grup/ Prueba Pnt./ } \\
\text { amam p/edad ventaja }\end{array}$ \\
$\leq 4$ mes. $12 \quad 14.80^{*}$ \\
$>4$ mes. $12 \quad+10.1$ \\
$\leq 4$ mes. $24 \quad+7.40^{* *}$ \\
$>4$ mes. $24+13.9$ \\
$* F=3.24 ; \quad p=.41$ \\
$* * F=3.76 ; p=.25$ \\
El análisis de regresión \\
indicó que la duración del \\
amamantamiento es aún \\
significativa en relación \\
con los puntajes IDM a \\
los 12 y 24 meses, aún \\
con factores de confu- \\
sión y puntajes HOGAR \\
que entran en el análisis.
\end{tabular} \\
\hline $\begin{array}{l}\text { Young } \\
\text { et al., } \\
1982\end{array}$ & $\begin{array}{l}\text { Estudio de correlación, } \\
\text { de corte transversal y re- } \\
\text { trospectivo. Medidas de } \\
\text { desarrollo mental y mo- } \\
\text { tor a los } 6,8,10,12,14 \\
\text { o } 16 \text { meses. Método de }\end{array}$ & $\begin{array}{l}1000 \text { bebés seleccio- } \\
\text { nados de la banca } \\
\text { de datos constitui- } \\
\text { dos por los regis- } \\
\text { tros de nacimientos } \\
\text { de Tunez. Igual }\end{array}$ & $\begin{array}{l}\text { Clase social no ve- } \\
\text { rificable. }\end{array}$ & $\begin{array}{l}\text { Puntajes IDM e } \\
\text { IDP de Bayley, ta- } \\
\text { maño y peso del } \\
\text { cuerpo, prevalecida } \\
\text { de enfermedades, } \\
\text { alegrias. }\end{array}$ & $\begin{array}{l}\text { Ventajas promedio del } \\
\text { IDM del amamantado } \\
\text { sobre combinación arti- } \\
\text { ficial y mixta de acuerdo } \\
\text { al sexo, SSE y edad: }\end{array}$ \\
\hline
\end{tabular}




\begin{tabular}{|c|c|c|c|c|c|}
\hline Estudio & Diseño del estudio & : Mursirta: & $\begin{array}{l}\text { Criterios de } \\
\text { exclusión }\end{array}$ & $\begin{array}{l}\text { Restitrado de } \\
\text { las rariables }\end{array}$ & $\begin{array}{l}\text { Resultados } \\
\text { stgrificativos }\end{array}$ \\
\hline & $\begin{array}{l}\text { alimentación usado e } \\
\text { informado por las ma- } \\
\text { dres. Sujetos clasificados } \\
\text { por método de alimen- } \\
\text { tación: artificial; amaman- } \\
\text { tados } \leq 2 \text { meses; mixto - } \\
\text { amamantados, dándoles } \\
\text { luego leche de vaca des- } \\
\text { pués de los } 2 \text { meses de } \\
\text { edad; y amamantados }>2 \\
\text { meses. }\end{array}$ & $\begin{array}{l}\text { número de bebés } \\
\text { de } 5 \text { clases sociales } \\
\text { representados por } \\
\text { cada grupo según } \\
\text { edad. }\end{array}$ & & $\begin{array}{l}\text { Factores de con- } \\
\text { fusión: } \mathrm{N}^{\circ} \text { de } \\
\text { hermanos, educa- } \\
\text { ción materna, fu- } \\
\text { mar, uso de alcohol. }\end{array}$ & $\begin{array}{l}+13.86(f=3.02 ; p>.01) ; \\
\text { en varones, alto SSE, } 10 \\
\text { meses } \\
+5.85(t=2.04 ; p<.05) \text { en } \\
\text { mujeres, alto SSE, } 10 \\
\text { meses } \\
+4.97(t=2.82 ; p<.01) \text { en } \\
\text { mujeres, bajo SSE, } 12 \\
\text { meses } \\
+5.93(t=2.77 ; p<.05) \text { en } \\
\text { varones, alto SSE, } 12 \\
\text { meses } \\
+3.50(t=1.92 ; p<.10) \text { en } \\
\text { varones, alto SSE, } 14 \\
\text { meses } \\
\text { No se encontró que algu- } \\
\text { na de los factores de } \\
\text { confusión influenciaran } \\
\text { los puntajes IDM. }\end{array}$ \\
\hline
\end{tabular}

Noota. LC-AGP: cadena larga de ácidos grasos polisaturados. IDM: Indice de Desarrollo Mental. IDP: Indice de Desarrollo Psicomotor. 
impuestas por dicha deficiencia en el rendimiento de niños en la Escala Motora de Bayley durante el segundo año de vida.

Será difícil encontrar el estudio ideal porque razones éticas no lo permiten. El probar la secuencia causal requiere un diseño con un seguimiento de niños anémicos que reciban aleatoriamente placebo o leche de pecho. Este diseño es factible pero no aceptable.

\section{B.2. Prevención secundaria (cuadro 4)}

En esta sección se discute el posible efecto preventivo que puede ofrecer la leche de pecho en el caso de niños prematuros o de niños que sufrieron un insulto cerebral temprano.

\section{B.2.1. Acidos grasos}

Durante el crecimiento intra-uterino la transferencia de nutrimentos de la madre al feto a través de la placenta satisface la necesidad de ácidos grasos no-esenciales, particularmente los no-polisaturados de larga cadera (AGNPLC). Igualmente, la leche materna es una rica fuente de ácido docosahexenoides y suple las necesidades de los bebés después del nacimiento (Uauy y Andraca, 1995). Recientemente se ha demostrado que estos ácidos grasos participan en el desarrollo de la retina y del cerebro. En el caso de las fórmulas comerciales, los contenidos del ácido docosahexenoides no son suficientes para los recién nacidos o para los bebés prematuros, como se ha demostrado por el bajo nivel del plasma del ácido docosahexenoide en aquellos bebés que fueron alimentado exclusivamente con fórmulas (Uauy y Andraca, 1995). En concordancia con esas observaciones se han reportado diferencias en la función visual y en algunos aspectos muy específicos del procesamiento de información entre los niños amamantados y los alimentados con fórmula (Kotlezko y Bremer, 1989).

En un estudio, se observó que a los cuatro meses de edad los bebés prematuros (edad ajustada) y los bebés de período completo que fueron 
alimentados con leche de pecho se desenvolvieron significativamente mejor, en pruebas de potenciales evocados visuales y en agudeza potencial de la mirada, que los bebés alimentados con fórmula. A los 36 meses los bebés que recibieron leche de pecho también se desenvolvieton mejor que los bebés alimentados con fórmula en pruebas que miden la agudeza visual y discriminación de caracteres visuales (E. Birch, D. Birch, D. Hoffman, L. Hale, M. Everett y R. Uauy, 1993).

Un estudio reciente (Agostoni, Trojan, Bellu, Riva y Giovannini, 1995) comparó el desempeño en la prueba de desarrollo psicomotor de BrunetLezine en tres grupos de sujetos que tomaron: leche materna, fórmula convencional (con precursores AGNPLC), o una fórmula experimental con un suplemento pre-elaborado del AGNPLC (cuadro 3). La edad de los sujetos elegibles variaba entre las 37 y las 42 semanas de gestación y estaban libres de cualquier tipo de desorden que hubiera podido ser diagnosticado clínicamente. Además, tenían puntajes Apgar de siete o mejor a las cinco minutos después del parto. Las madres de 30 de los sujetos escogieron amamantar a sus bebés mientras que los sujetos restantes fueron asignados al azar a recibir bien la fórmula convencional $(n=31)$ o la fórmula experimental $(n=29)$. No hubo diferencias entre los tres grupos en la educación de los padres o en otras variables sociales y económicas.

La prueba de Brunet-Lezine ${ }^{3}$ se administró a 86 de los sujetos a las 4 meses de edad. El puntaje medio en la prueba de Brunet-Lezine para todos los sujetos fue $101(\mathrm{SD}=11)$ y el rango fue de 80-136. Los bebés que recibieron la fórmula enriquecida con GNPLC o leche materna obtuvieron un puntaje significativamente más alto $(105.3$ y 102.2 , respectivamente) que los sujetos que recibieron la fórmula convencional (96.5). Los análisis de sangre efectuados a un sub-grupo de bebés revelaron que los niveles de ácido graso fueron más altos en los bebés que recibieron la fórmula enriquecida con GNPLC o con leche de pecho.

3. La prueba de Brunet-Lezine evalúa las funciones motoras gruesas y finas, las respuestas sociales y el lenguaje. Los resultados de las sub-escalas son agregadas para obtener un puntaje del cociente del desarrolio. 


\section{Cuadro 4}

Estudios sobre los Eectos Secundarios Preventivos del Amamantamiento

\begin{tabular}{|c|c|c|c|c|c|}
\hline Estudio & Diseno del estudio & Muestra & $\begin{array}{l}\text { Chrterios de } \\
\text { excerision }\end{array}$ & $\begin{array}{l}\text { Resultado de: } \\
\text { las yariables: }\end{array}$ & $\begin{array}{l}\text { Resultados: } \\
\text { significativos }\end{array}$ \\
\hline $\begin{array}{l}\text { Lucas } \\
\text { et al., } \\
1989\end{array}$ & $\begin{array}{l}\text { Ensayo al azar, longi- } \\
\text { tudinal, prospectivo, } \\
\text { comparando los efectos } \\
\text { de la LPD y la FPT. Do- } \\
\text { nadas en el desarrollo del } \\
\text { comportamiento de los } \\
\text { bebés pretérmino. Los } \\
\text { sujetos recibieron el tra- } \\
\text { tamiento hasta ser dados } \\
\text { de alta del hospital o has- } \\
\text { ta alcanzar un peso de } \\
2000 \text { g. Datos sobre el } \\
\text { comportamiento obteni- } \\
\text { dos a los } 9 \text { meses. Suje- } \\
\text { tos clasificados en } 2 \text { gru- } \\
\text { pos de acuerdo a la deci- } \\
\text { sión de la madre de ama- } \\
\text { mantar o no. Dentro de } \\
\text { cada grupo, sujetos asig- } \\
\text { nados al azar para recibir } \\
\text { LPD o FPT vía un tubo } \\
\text { nasogástrico mientras es- } \\
\text { taban en el hospital. El } \\
\text { tratamiento se dio como } \\
\text { un suplemento de la }\end{array}$ & $\begin{array}{l}502 \text { bebés pretér- } \\
\text { mino nacidos en } 3 \\
\text { hospitales en Ingla- } \\
\text { terra y admitidos en } \\
\text { la unidad de cuida- } \\
\text { dos especiales. } \mathrm{N}^{\circ} \\
\text { de sujetos incluidos } \\
\text { en el análisis final: } \\
\text { grupo amamantado } \\
\text { - leche materna } \\
\text { y LPD ( } \mathrm{n}=170) ; \mathrm{le}- \\
\text { che materna y FPT } \\
\text { ( } n=173) ; \text { grupo } n o \\
\text { amamantado-LPD } \\
\text { solo }(n=83) ; \mathrm{FPT} \\
\text { solo }(n=76) \text {. }\end{array}$ & $\begin{array}{l}\text { Peso al nacer }>1850 \\
\text { g. Anomalías con- } \\
\text { génitas mayores. }\end{array}$ & \begin{tabular}{|l|} 
Puntajes en el desa- \\
rrollo del inventa- \\
rio en la pantalla de \\
Knobloch y otros a \\
los 9 meses. Eva- \\
luación de cinco \\
áreas del compor- \\
tamiento: comp. \\
adaptativo, motori- \\
cidad gruesa, motri- \\
cidad fina, lenguaje \\
y personalidad so- \\
cial. CD total obte- \\
nido promediando \\
los puntajes en to- \\
das las escalas.
\end{tabular} & 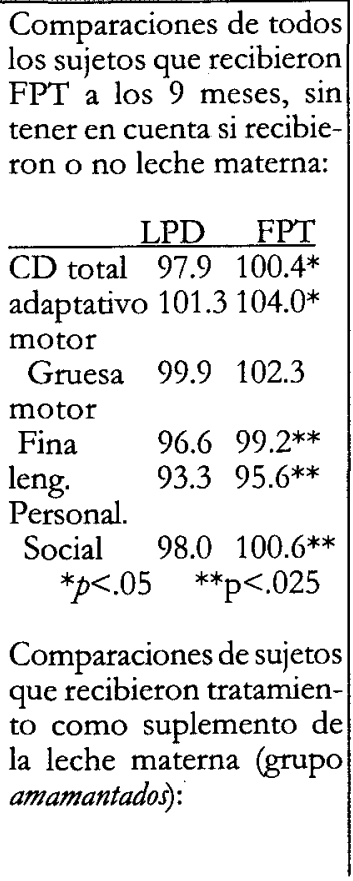 \\
\hline
\end{tabular}




\begin{tabular}{|c|c|c|c|c|c|}
\hline Estudiso & Piscâo del estudio & Minestra & $\begin{array}{l}\text { Criterios de } \\
\text { exclusion }\end{array}$ & Resuluadis de & : rigrificatrvos \\
\hline & $\begin{array}{l}\text { leche materna a bebés cu- } \\
\text { yas madres escogieron } \\
\text { amamantarlos y como } \\
\text { una dieta base a los be- } \\
\text { bés cuyas madres no es- } \\
\text { cogieron amamantarlos. }\end{array}$ & & & & \begin{tabular}{lcc} 
& LPD & FPT \\
CD total & 98.2 & $101.2^{*}$ \\
adaptativo & 102.1 & $105.0^{* *}$ \\
motor. & & \\
Gruesa & 100.4 & 103.7 \\
motor. & & \\
Fina & 97.2 & $100.0^{* *}$ \\
leng. & 93.1 & $95.8^{* *}$ \\
Personalidad & \\
Social & 97.7 & $101.5^{* *}$ \\
${ }^{*} p<.05$ & $* * p<.025$ \\
\multicolumn{4}{c}{} \\
Comparaciones de sujetos \\
que recibieron tratamien- \\
tos como dieta base (gru- \\
po no amamantados) no fue- \\
ron significativos.
\end{tabular} \\
\hline $\begin{array}{l}\text { Lucas } \\
\text { et al., } \\
1994\end{array}$ & $\begin{array}{l}\text { Ensayo al azar, longi- } \\
\text { tudinal y prospectivo, } \\
\text { comparando los efectos } \\
\text { de la PLPD y la FPT. } \\
\text { Datos sobre el desempe- } \\
\text { ño mental y motor al- } \\
\text { canza de los } 10 \text { meses. }\end{array}$ & $\begin{array}{l}502 \text { bebés pretér- } \\
\text { mino nacidos en } 3 \\
\text { hospitales en Ingla- } \\
\text { terra y admitidos a } \\
\text { unidad de cuida- } \\
\text { dos intensivos. }\end{array}$ & $\begin{array}{l}\text { Peso al nacer }>1850 \\
\text { g. Anomalias con- } \\
\text { génitas mayores }\end{array}$ & $\begin{array}{l}\text { Puntajes IDM e } \\
\text { IDP de Bayley a los } \\
18 \text { meses. }\end{array}$ & $\begin{array}{l}\text { No hubo efectos signifi- } \\
\text { cativos del tipo de trata- } \\
\text { miento (LPD o FPT) o de } \\
\text { presencia o ausencia de } \\
\text { amamantamiento en } \\
\text { puntajes IDM e IDP. }\end{array}$ \\
\hline
\end{tabular}




\begin{tabular}{|c|c|c|c|c|c|}
\hline I: Iration: & Diseño del estudio & Muestra: & $\begin{array}{l}\text { Criterios de } \\
\text { exclusión }\end{array}$ & $\begin{array}{l}\text { Resultado de } \\
\text { las variallies }\end{array}$ & $\begin{array}{l}\text { Resuladios: } \\
\text { significativos }\end{array}$ \\
\hline & $\begin{array}{l}\text { Sujetos clasificados en } 2 \\
\text { grupos de acuerdo a la } \\
\text { decisión de la madre de } \\
\text { amamantar o no. Den- } \\
\text { tro de cada grupo, suje- } \\
\text { tos asignados al azar para } \\
\text { recibirLPD o FPT vía un } \\
\text { tubo nasogástrico mien- } \\
\text { tras estaban en el hospi- } \\
\text { tal. El tratamiento se dio } \\
\text { como un suplemento de } \\
\text { la leche materna a bebés } \\
\text { cuyas madres escogieron } \\
\text { amamantarlos, y como } \\
\text { una dieta base a los be- } \\
\text { bés cuyas madres no es- } \\
\text { cogieron hacerlo. }\end{array}$ & $\begin{array}{l}\mathrm{N}^{\circ} \text { de sujetos in- } \\
\text { cluidos en el análisis } \\
\text { final: grupo ama- } \\
\text { mantado - leche } \\
\text { materna y LPD } \\
(n=134) ; \text { leche ma- } \\
\text { terna y FPT } \\
(n=139) ; \text { grupo no } \\
\text { amamantado-LPD } \\
\text { solo }(n=62) ; \mathrm{FPT} \\
\text { solo }(n=52) \text {. }\end{array}$ & & & \\
\hline $\begin{array}{l}\text { Lucas } \\
\text { et al., } \\
1992\end{array}$ & $\begin{array}{l}8 \text { años de seguimiento } \\
\text { del desarrollo mental de } \\
\text { bebés pretérmino par- } \\
\text { ticipantes en dos ensayos } \\
\text { prospectivos, al azar. } \\
\text { El ensayo } 1 \text { comparó los } \\
\text { efectos de la fórmula } \\
\text { normal y FPT en el }\end{array}$ & $\begin{array}{l}300 \text { niños de } 7.5-8 \\
\text { años nacidos pre- } \\
\text { término y admiti- } \\
\text { dos en la unidad de } \\
\text { cuidados especiales } \\
\text { en } 5 \text { hospitales de } \\
\text { Inglaterra. }\end{array}$ & $\begin{array}{l}\text { Peso al nacer }>1850 \\
\text { g. Anomalías con- } \\
\text { génitas mayores }\end{array}$ & $\begin{array}{l}\text { Puntajes en la prue- } \\
\text { ba EINW-R abre- } \\
\text { viada a los } 7.5-8 \\
\text { años. }\end{array}$ & $\begin{array}{l}\text { Ventajas del puntaje pro- } \\
\text { medio para niños ama- } \\
\text { mantados v. no amamanta- } \\
\text { dos en varias escalas } \\
\text { EINW-R: }\end{array}$ \\
\hline
\end{tabular}




\begin{tabular}{|c|c|c|c|c|c|}
\hline Estudio & Piscio del estudio & Muestra & $\begin{array}{l}\text { Criterios de } \\
\text { exclusión }\end{array}$ & $\begin{array}{l}\text { Resultado de } \\
\text { las variables }\end{array}$ & $\begin{array}{l}\text { Resultados: } \\
\text { significativos }\end{array}$ \\
\hline & $\begin{array}{l}\text { desempeño mental y } \\
\text { motor de los bebés pre- } \\
\text { término a los } 10 \text { meses. } \\
\text { El ensayo } 2 \text { comparó los } \\
\text { efectos dela LPD yla FPT } \\
\text { en el desempeño mental } \\
\text { y motor de bebés pretér- } \\
\text { mino a los } 9 \text { y } 18 \text { meses. } \\
\text { El tratamiento se dio co- } \\
\text { mo un suplemento de la } \\
\text { leche materna a bebés cu- } \\
\text { yas madres escogieron } \\
\text { amanantarlos y como } \\
\text { una dieta base a los be- } \\
\text { bés cuyas madres no es- } \\
\text { cogieron hacerlo. Sujetos } \\
\text { clasificados en } 2 \text { grupos } \\
\text { según fueron amaman- } \\
\text { tados o no: amamantados } \\
\text { +tratamiento ( } n=210 \text { ); y } \\
\text { no amamantados (tratamien- } \\
\text { to sólo) (n=90). Los da- } \\
\text { tos sobre el desempeño } \\
\text { mental se obtuvieron a } \\
7.5-8 \text { años. }\end{array}$ & & & & $\begin{array}{lr}\text { Escala } & \text { Ventaja } \\
\text { verbal } & +10.1 \\
\text { desempeño } & +10.1 \\
\text { CI total } & +10.2 \\
& (p<.001) \\
& \\
\text { Análisis de los resultados } \\
\text { de los ensayos al azar (ej., } \\
\text { fórmula normal vs LPD y } \\
\text { FPT vs LPD) no reporta- } \\
\text { dos. }\end{array}$ \\
\hline
\end{tabular}




\begin{tabular}{|c|c|c|c|c|c|}
\hline Estudion & Diseño del estudío & Muestra & $\begin{array}{l}\text { Critetios de } \\
\text { exclustón }\end{array}$ & $\begin{array}{l}\text { Resulado de } \\
\text { las varabiles. }\end{array}$ & Restiltados \\
\hline $\begin{array}{l}\text { Lanting } \\
\text { et al., } \\
1994\end{array}$ & $\begin{array}{l}\text { Estudio de correlación, } \\
\text { retrospectivo, para exa- } \\
\text { minar la relación entre el } \\
\text { método de alimentación } \\
\text { de bebés y el desarrollo } \\
\text { de desordenes neuroló- } \\
\text { gicos en la infancia. Suje- } \\
\text { tos clasificados inmedia- } \\
\text { tamente después de na- } \\
\text { cer dentro de los estatuas } \\
\text { neurológicos normal, } \\
\text { casi-anormal, o abier- } \\
\text { tamente anormal en base } \\
\text { a un examen neurológico } \\
\text { escandalizado. Los suje- } \\
\text { tos seleccionados para el } \\
\text { seguimiento dieron un } \\
\text { examen neurológico es- } \\
\text { tandarizado a los } 9 \text { años. } \\
\text { Sujetos clasificados de } \\
\text { acuerdo a las prácticas ali- } \\
\text { menticias en base a un } \\
\text { cuestionario llenado por } \\
\text { los padres: alimentados con } \\
\text { fórmula (n=358); amaman- }\end{array}$ & $\begin{array}{l}\text { Seleccionados de } \\
\text { una cohorte de } \\
3162 \text { bebés nacidos } \\
\text { entre } 1975-78 \text { en un } \\
\text { hospital en Holan- } \\
\text { da. }\end{array}$ & $\begin{array}{l}\text { Datos incompletos } \\
\text { sobre alimentación. } \\
\text { Las madres no pu- } \\
\text { dieron recordar las } \\
\text { prácticas de alimen- } \\
\text { tación Bebés pre- } \\
\text { término, Bebé ad- } \\
\text { mitido en custodia } \\
\text { en cuidados especia- } \\
\text { les. }\end{array}$ & $\begin{array}{l}\text { Desempeño en el } \\
\text { examen neuroló- } \\
\text { gico a los } 9 \text { años. } \\
\text { Estado neuroló- } \\
\text { gico clasificado co- } \\
\text { mo disfunción menor } \\
\text { grado } 1 \text { (pocos sín- } \\
\text { tomas), disfunción } \\
\text { menor-grado } 2 \text { (más } \\
\text { síntomas, o anor- } \\
\text { mal). }\end{array}$ & $\begin{array}{l}\text { Para el análisis, sujetos } \\
\text { amamantados con fórmu- } \\
\text { la y suplemento al menos } \\
3 \text { semanas, se combinaron } \\
\text { con sujetos exclusivamen- } \\
\text { te amamantados al menos } \\
3 \text { semanas. Para todos los } \\
\text { sujetos amamantados al } \\
\text { menos } 3 \text { semanas, a pesar } \\
\text { de la clasificación neuroló- } \\
\text { gica al nacer, puntajes en el } \\
\text { examen neurológico a los } \\
9 \text { años y fue alta la proba- } \\
\text { bilidad de ser clasificados } \\
\text { como normales a los } 9 \\
\text { años. }\end{array}$ \\
\hline
\end{tabular}




\begin{tabular}{|c|c|c|c|c|c|}
\hline Estrudio & Diseno del estridio & : Muestra & $\begin{array}{l}\text { Criterios de } \\
\text { exclusion? }\end{array}$ & $\begin{array}{l}\text { Resulatio de } \\
\text { las vatiables? }\end{array}$ & t. \\
\hline & $\begin{array}{l}\text { tados con fórmula y suple- } \\
\text { mento al menos } 3 \text { semanas } \\
(n=33) \text {; y exclusivamente } \\
\text { amamantados almenos } 3 \text { se- } \\
\text { manas }(n=135) \text {. }\end{array}$ & & & & \\
\hline $\begin{array}{l}\text { Menkes, } \\
1977\end{array}$ & $\begin{array}{l}\text { Estudio de correlación, } \\
\text { transversal, retrospectivo } \\
\text { para examinar la relación } \\
\text { entre el método de ali- } \\
\text { mentación para bebés y } \\
\text { el desarrollo de la inhabi- } \\
\text { lidad para el aprendizaje } \\
\text { en la niñez. Los sujetos } \\
\text { fueron clasiffcados como } \\
\text { aquellos con desordenes } \\
\text { en el aprendizaje y un } \\
\text { grupo de control de ni- } \\
\text { ños con otros desorde- } \\
\text { nes neurológicos. Niños } \\
\text { amamantados fueron } \\
\text { definidos como aquellos } \\
\text { que recibieron leche de } \\
\text { pecho al menos por } 4 \text { se- } \\
\text { manas. }\end{array}$ & $\begin{array}{l}\text { Sujetos con desor- } \\
\text { denes en el apren- } \\
\text { dizaje fueron } 29 \text { ni- } \\
\text { ños blancos de cla- } \\
\text { se media nacidos } \\
\text { entre-1959-70 y en- } \\
\text { viados al autor para } \\
\text { tratamiento y eva- } \\
\text { luación neuroló- } \\
\text { gica. Los sujetos } \\
\text { controlados eran } \\
\text { pacientes del autor } \\
\text { quien los presentó } \\
\text { como con una va- } \\
\text { riedad de desorde- } \\
\text { nes neurológicos. } \\
\text { Los sujetos fueron } \\
\text { emparejados por } \\
\text { sexo y edad ( } n=53 \text { ). }\end{array}$ & $\begin{array}{l}\text { Bebés pretérmino } \\
\text { (no se dio defini- } \\
\text { ción). Malformacio- } \\
\text { nes con génitas } \\
\text { mayores. Bebés cu- } \\
\text { yos métodos de ali- } \\
\text { mentación se deter- } \\
\text { minaron de acuerdo } \\
\text { a circunstancias. }\end{array}$ & $\begin{array}{l}\text { Los sujetos en los } \\
\text { grupos con desor- } \\
\text { denes en el apren- } \\
\text { dizaje y de control } \\
\text { fueron clasificados } \\
\text { como amamantados } \\
\text { o alimentados con bi- } \\
\text { berón. }\end{array}$ & $\begin{array}{l}13.8 \% \text { de los niños con } \\
\text { desordenes en el aprendi- } \\
\text { zaje y } 47.2 \% \text { de los niños } \\
\text { de control fueron ama- } \\
\text { mantados }(p=.004) \text {. }\end{array}$ \\
\hline
\end{tabular}

Nota. LPD: leche de pecho en depósito. CD: Cociente de Desarrollo. CI: Cociente de Inteligencia. IDM: Indice de Desarrollo Mental; IDP: Indice de Desarrollo Psicomotor; FPT, Fórmula pretérmino. EINW-R: Escala de Inteligencia para Niños de Wechsler, versión revisada del Reino Unido. 


\section{B.2.2. Discusión}

Los estudios ya resumidos y otros similares (R. Uauy, D. Birch, E. Birch, J. Tyson y D. Hoffman, 1990) nos ayudan a comprender las implicaciones biológicas del amamantamiento y las relaciones entre la leche de pecho, AGNPLC y funciones cerebrales específicas. Se debe reconocer sin embargo que los datos no están directamente relacionados con la contribución de la leche de pecho a la inteligencia ("g"). Ni la teoría, ni los datos empíricos sugieren que la agudeza visual, el potencial de evocación visual, o discriminación visual de caracteres durante los primeros meses de vida, sean precursores del desarrollo de habilidades intelectuales mas generales, como el razonamiento. Además, aunque la Prueba de Brunet-Lezine, la Escala de Bayley de Desarrollo Mental, y otras escalas del desarrollo son herramientas útiles para describir el repertorio del comportamiento de los bebés de cuatro meses de edad, en la mayoría de los casos los puntajes de estas escalas no predicen el desempeño posterior sea a los 24 meses o mas adelante.

\section{B.2.3. Leche de pecho y bajo peso al nacer}

Algunos estudios (Lucas, Morley, Cole, Gove, Davis, Bamford y Dossettor, 1989; Lucas, Morley, Cole, Lister, Leeson-payne 1992) han publicado una serie de estudios sobre los efectos a corto y largo plazo del amamantamiento y de la alimentación por fórmula en el desempeño en pruebas de desarrollo mental y de inteligencia (CI) en niños nacidos prematuramente con muy bajo peso $(<1.850 \mathrm{gr})^{4}$. Una limitación de los datos respectivos es que si bien los estudios estuvieron interrelaccionados, la definición de las muestras fue muy restringida y los tres informes no discriminaron entre los sujetos que participaron en uno o en mas estudios.

4. Generalmente el período de gestación es de los 38 a 42 semanas, y en la mayoría de los recién nacidos el peso corporal es $>2,500$ gramos. Se han establecido también los pesos que deben tener los bebés aun cuando su período de gestación haya sido menor a las 38 semanas. 
En el primer informe (I) (Lucas et al., 1989) se comparó el desarrollo de los bebés nacidos antes de término (peso $\leq 1850 \mathrm{~g}$ ) que fueron admitidos a las unidades de recién nacidos en Cambridge, Ipswich, o King's Lynn, Inglaterra, desde 1982 a 1984. Estos bebés fueron asignados al nacer a una de dos intervenciones. La primera era leche de pecho (LP) que había sido donada mientras la segunda era leche de fórmula $(2 \mathrm{~g}$. proteína; $0.335 \mathrm{MJ} ; 35 \mathrm{mg}$. fósforo; $70 \mathrm{mg}$. calcio; $45 \mathrm{mg}$. sodio; 100 $\mathrm{ml})$ para bebés prematuros (FPT). Las madres en este primer estudio habían decidido no suministrar su propia leche a sus vástagos. En el segundo estudio (II) se incluyo vástagos de mujeres que eligieron extraer su propia leche para alimentar a sus niños. Estos niños fueron también asignados al azar, bien al LP o al FPP para complementar la alimentación del bebé. En los estudios I y II las dietas se discontinuaron cuando los niños fueron separados de la unidad de recién nacidos o cuando su peso era $\geq 2,000 \mathrm{~g}$.

A los nueve meses de edad se efectuaron comparaciones entre grupos en el desempeño de los bebés en la escala de Knobloch, Pasamanick y Sherard (1966; Lucas et al., 1992), que incluye cinco áreas del desarrollo (adaptación, motoricidad gruesa, motoricidad fina, lenguaje y social-personal $)^{5}$.

Para los propósitos de los análisis estadísticos se combinaron los estudios I y II, y se observó que a los 9 meses de edad los bebés que recibieron la FPP, como dieta básica o como un suplemento, tenían un puntaje significativamente más alto en las áreas de adaptación, motor fino, lenguaje y social-personal que aquellos que recibieron LP. Además, en el caso particular del estudio II, aquellos sujetos que recibieron la FPP tenían un cociente del desarrollo más alto que aquellos que recibieron LP, así como puntajes más altos en las subescalas de adaptación, lenguaje y social-

5. Esta prueba es más un inventario de tamizaje que una escala del desarrollo, las cuales son generalmente reconocidas como tests de desarrollo mental. Sin embargo, Lucas y su otros prefirieron definir a la prueba de Knobloch como escala de desarrollo. Además de la escala los bebés también pasaron por un examen neurológico (AmielTison y Granier), que permitía clasificar a los bebés en una de tres categorias de riesgo. 
personal. Un análisis que se focalizó exclusivamente en aquellos bebés que recibieron algo de leche de sus propias madres mostró que los que habían recibido más del $50 \%$ de su ingestión total de LP tenían puntajes comparativamente más bajos.

Una conclusión natural de estos datos es que a diferencia de lo que se podía esperar, los bebés prematuros que fueron alimentados con FPP y con las especificaciones enumeradas tenían un desarrollo mental y motor más avanzado que el de aquellos alimentados con LP. Los autores subrayaron que parte de la importancia de este hallazgo es que el inventario de tamizaje incluye muchos de los items del programa de Gesell, el cual de acuerdo a los autores tiene valor predictivo de la inteligencia posterior. Sin embargo, pese a la defensa de los autores, hay muchos estudios sobre desarrollo infantil en niños sin riesgo clínico que han mostrado precisamente lo contrario; esto es, que la validez predictiva de las escalas del desarrollo administradas durante los primeros 12 meses de vida no es diferente de cero (Colombo, 1993).

En un seguimiento a los 18 meses de edad, Lucas et al. (1989; Lucas, Morley, Cole y Gore, 1994) evaluaron 387 de los bebés de la muestra original con las escalas de desarrollo mental y motor de Bayley. A diferencia de lo que se observó a los 9 meses, a los 18 meses no se encontraron ventajas para los sujetos que habían recibido FPP. Los bebés alimentados con LP se desempeñaron tan bien como los sujetos de FPP en las dos escalas de desarrollo. Los autores sugieren que la ausencia de diferencias se puede deber a la recuperación de los sujetos con deficiencias nutricionales tempranas.

En el tercer artículo, Lucas et al. (1992) informaron sobre los efectos de la leche de pecho en los cocientes de inteligencia obtenidos cuando los niños tenían siete a ocho años de edad (cuadro 4). Los sujetos que participaron fueron admitidos en las unidades de cuidados especiales para bebés de Cambridge, Ipswich, King's Lynn, Norwich y Sheffield entre enero de 1982 y marzo de 1985. Dos de estas unidades de cuidados (Norwich y Sheffield) no fueron incluidas en el estudio publicado en 1989. 
Incluso en el primer estudio los sujetos fueron seleccionados hasta 1984, mientras que en este tercer estudio el reclutamiento se extendió a marzo de 1985. Los autores no especifican el grado de coincidencias entre los sujetos de los diferentes artículos (Lucas et al., 1994). Sin embargo, sugieren que todos los sujetos participaron en un momento u otro en los estudios I y II.

Entre los siete y medio y ocho años de edad, los niños que recibieron la leche expresamente extraída de sus propias madres (grupo 2) obtuvieron un CI (Test Wechsler para niños) superior al de aquellos cuyas madres escogieron no proveerles de leche de pecho (grupo 1). Las diferencias se observaron en la Escala Verbal y en la Escala Total (grupo 1: 92.8; grupo 2: 103) del Test de Inteligencia de Wechsler. En un análisis que se redujo al grupo 2 se observó una relación positiva entre el volumen de leche que tomaron y el CI. Además, el CI de los que tomaron menos era equivalente al grupo 1.

En conclusión, la alimentación con leche materna mejoró el CI a los 7 u 8 años de edad en niños prematuros con muy bajo peso, en comparación con los CI de niños prematuros que no recibieron leche materna y que recibieron FPP, leche de pecho donada con gotero, madura y pasteurizada, o una fórmula calificada. Los autores concluyeron que los datos sustentan la hipótesis causal de que la leche de pecho promueve el desarrollo neural de los bebés prematuros.

\section{B.2.4. Riesgo neurológico}

Lanting et al. (Lanting, Fidler, Huisman, Touwen y Boersma, 1994) estudiaron la relación entre el método de alimentación y el funcionamiento neurológico a los nueve años de edad (cuadro 4). En base a un examen neurológico después del parto formaron tres grupos de niños. Un grupo $(n=60)$ fue definido como neurológicamente anormal (ej., hemisíndrome, hipotonia, hipertonia); un segundo grupo incluyó una muestra al azar de niños $(n=322)$ con anormalidades menores (ej., hipotonía moderada), y el tercero estuvo compuesto por muestra al azar de niños normales $(n=322)$. 
Nueve años después de nacer se les efectuó a los niños un nuevo examen neurológico que sirvió para clasificarlos nuevamente como normales; con una disfunción neurológica menor (dos signos); o anormales. Durante este examen también se obtuvo información sobre las prácticas de alimentación temprana. Así, se formaron tres grupos de alimentación: exclusivamente por fórmula; de pecho más fórmula dentro de las tres primeras semanas del nacimiento; y exclusivamente de pecho por lo menos durante tres semanas.

Los resultados mostraron que a los nueve años de edad los niños que fueron exclusivamente amamantados tenían mayores probabilidades que el resto de los niños de ser clasificados como neurológicamente normales. Además, entre los niños clasificados con disfunciones neurológicas menores durante el período neonatal, aquellos que fueron amamantados tuvieron menos probabilidades de tener disfunciones neurológicas menores a los 9 años de edad. La frecuencia de anormalidades neurológicas menores fue dos veces más alta para los niños alimentados con fórmula que aquellos que fueron amamantados. Los autores sugieren que el tipo de alimentación durante las primeras semanas de vida juega un rol en el desarrollo posterior del comportamiento ${ }^{6}$.

\section{B.3. Discusión}

Los estudios sobre ácidos grasos esenciales y los estudios longitudinales de bebés nacidos a término muestran el valor biológico del amamantamiento. La más clara ilustración está en que el desarrollo de la retina y de algunos sistemas neuronales cerebrales de los primates y del ser humano dependan del ácido docosahexenoides, el cual es un componente básico de la leche de pecho. El estudio longitudinal de niños con un peso $<1,850$ gramos es también muy sugestivo. Los dos grupos de estudios muestran que los que más necesitan lactar son los bebés prematuros y los bebés de muy

6. Ver también Menkes, 1977. 
bajo peso al nacer. Recordemos que en la sección sobre prevención primaria también se observó que la leche de pecho es particularmente importante entre los prematuros por su vulnerabilidad a la anemia ferropénica.

Sin embargo, es necesario tener cautela con la interpretación de estos resultados y no hacer generalizaciones que van más allá del significado exacto de los datos. Los efectos de los ácidos grasos en la retina y en ciertos sistemas neuronales son bastante específicos y se refieren posiblemente a microelementos dentro de la arquitectura del aparato cognitivo del niño. Las medidas de potencial evocado y agudeza visual a los cuatro meses no tiene una relación obvia con el desarrollo de las habilidades de atención o de habituación visual (Colombo, 1993). Esta diferenciación es importante por cuanto estas dos medidas visuales son predictivas del desarrollo intelectual posterior.

Hay una aparente contradicción entre los resultados de los estudios de ácidos grasos y los resultados de uno de los estudios publicados por Lucas et al. Mientras los primeros muestran que las fórmulas comerciales no les dan a los bebés ácidos necesarios para el desarrollo cerebral, el estudio longitudinal muestra que el rendimiento mental de los niños a los nueve meses que reciben fórmula rinden mejor que los niños que reciben leche de pecho. Al contemplar esta diferencia es importante anotar que la información sobre la composición de los productos lácteos usados en los estudios de Lucas no es lo suficientemente detallada para diferenciarlas de los productos usados en los estudios de ácidos grasos. Además, estos últimos estudios, como ya se dijo, fijaron en funciones muy específicas mientras que las escalas usadas por Lucas median sistemas conductuales generales.

Es obvio que con la información que hoy se tiene no es posible llegar a conclusiones definitivas. Sin embargo, es claro que los resultados invitan a nuevas investigaciones. Esta atención debe ser extendida a estudios sobre la función preventiva que puede tener el amamantamiento en niños que sufrieron un daño cerebral temprano. 


\section{Cuadro 5}

Estudios sobre la Leche de Pecho como un Factor de Riesgo

\begin{tabular}{|c|c|c|c|c|c|}
\hline Estudio & Diseño del estudio & Muestra & $\begin{array}{l}\text { Criterioside } \\
\text { enchision. }\end{array}$ & $\begin{array}{l}\text { Resultado de } \\
\text { las vatiables: }\end{array}$ & $\begin{array}{l}\text { Resultados } \\
\text { significativos }\end{array}$ \\
\hline $\begin{array}{l}\text { Little } \\
\text { et al., } \\
1989\end{array}$ & $\begin{array}{l}\text { Estudio de correlación } \\
\text { perspectivo y longitu- } \\
\text { dinal para examinar los } \\
\text { efectos del uso materno } \\
\text { del alcohol durante la lac- } \\
\text { tancia en el desarrollo } \\
\text { mental y motor del bebé. } \\
\text { Desarrollo mental y mo- } \\
\text { tor medidos a los } 12 \text { me- } \\
\text { ses. Uso materno de alco- } \\
\text { hol medido por un cues- } \\
\text { tionario durante } 1 \text { y } 3 \\
\text { meses. Niños amaman- } \\
\text { tados definidos como } \\
\text { aquellos que reciben la } \\
\text { mayoria de lo ingerido a } \\
\text { través de la leche de pe- } \\
\text { cho (<16 onzas al día de } \\
\text { leche no humana o su- } \\
\text { plemento). }\end{array}$ & $\begin{array}{l}400 \text { niños, la mayo- } \\
\text { ría blancos y de cla- } \\
\text { se media, nacidos } \\
\text { de madres pertene- } \\
\text { cientes a una orga- } \\
\text { nización para el } \\
\text { mantenimiento de } \\
\text { la salud en Seattle, } \\
\text { Washington }\end{array}$ & $\begin{array}{l}\text { Ningún cuidado } \\
\text { prenatal antes de } 6 \\
\text { meses de gestación. }\end{array}$ & \begin{tabular}{|l|} 
Puntajes IDM y \\
IDP de Bayley a los \\
12 meses. Variable \\
independiente: \\
puntaje AA infan- \\
til, usado para indi- \\
car la exposición in- \\
fantil al alcohol vía \\
leche de pecho, es- \\
timado de reportes \\
sobre madres con \\
consumo diario de \\
alcohol y dias de \\
amamantamiento \\
pormes durante 1a \\
3 meses.
\end{tabular} & $\begin{array}{l}\text { El puntaje AA infantil no } \\
\text { relacionado a los puntajes } \\
\text { IDM a los } 12 \text { meses. Se } \\
\text { encontró significativa ten- } \\
\text { dencia para los efectos del } \\
\text { puntaje AA infantil en el } \\
\text { puntaje IDP a los } 12 \text { me- } \\
\text { ses }(\not<.006) . \\
\begin{array}{lrr}\text { Punt. AA } & n & \text { IDP } \\
0 & 111 & 104 \\
0-0.4 & 188 & 103 \\
0.5-0.9 & 71 & 99 \\
1-1.4 & 25 & 98 \\
\geq 15 & 4 & 85\end{array}\end{array}$ \\
\hline $\begin{array}{l}\text { Astley y } \\
\text { Little, } \\
1990\end{array}$ & $\begin{array}{l}\text { Estudio de correlación } \\
\text { longitudinal para exami- } \\
\text { nar la relación entre el uso }\end{array}$ & $\begin{array}{l}323 \text { niños, la mayo- } \\
\text { ría blancos y de cla- } \\
\text { se media, nacidos }\end{array}$ & $\begin{array}{l}\text { Bebés no amam- } \\
\text { antados al menos } 2 \\
\text { semanas. Bebés que }\end{array}$ & $\begin{array}{l}\text { Puntajes IDM e } \\
\text { IDP de Bayleya los } \\
12 \text { meses. Variable }\end{array}$ & $\begin{array}{l}\text { Efectos no significativos } \\
\text { de exposición a la mari- } \\
\text { huana en los puntajes }\end{array}$ \\
\hline
\end{tabular}




\begin{tabular}{|c|c|c|c|c|c|}
\hline Esstudio & Piseño del estudio & 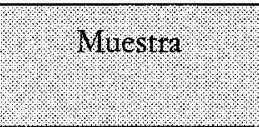 & $\left\{\begin{array}{l}\text { (1) } \\
\text { : }\end{array}\right.$ & Resulindo de & $\begin{array}{l}\text { Resultaclos: } \\
\text { significativos }\end{array}$ \\
\hline & $\begin{array}{l}\text { materno de marihuana } \\
\text { durante la lactancia en el } \\
\text { desarrollo mental y mo- } \\
\text { tor del bebé. Desempe- } \\
\text { ño mental y motor me- } \\
\text { didos a los } 12 \text { meses. } \\
\text { Niños amamantados de- } \\
\text { finidos como aquellos } \\
\text { que reciben la mayoría de } \\
\text { lo ingerido a través de la } \\
\text { leche de pecho (< } 16 \text { on- } \\
\text { zas al dia de leche no hu- } \\
\text { mana o suplemento) por } \\
\text { lo menos } 2 \text { semanas. }\end{array}$ & $\begin{array}{l}\text { de madres pertene- } \\
\text { cientes a una orga- } \\
\text { nización para el } \\
\text { mantenimiento de } \\
\text { la salud en Seattle, } \\
\text { Washington. }\end{array}$ & $\begin{array}{l}\text { no tuvieron } 12 \text { me- } \\
\text { ses de evalúo. }\end{array}$ & $\begin{array}{l}\text { independiente: be- } \\
\text { bés expuestos al } \\
\text { uso materno de } \\
\text { marihuana durante } \\
\text { la lactancia esti- } \\
\text { mados a través de } \\
\text { reportes sobre uso } \\
\text { materno diario de } \\
\text { marihuana y los } \\
\text { días de amaman- } \\
\text { tamiento por mes } \\
\text { durante } 1 \text { a } 3 \text { meses. }\end{array}$ & 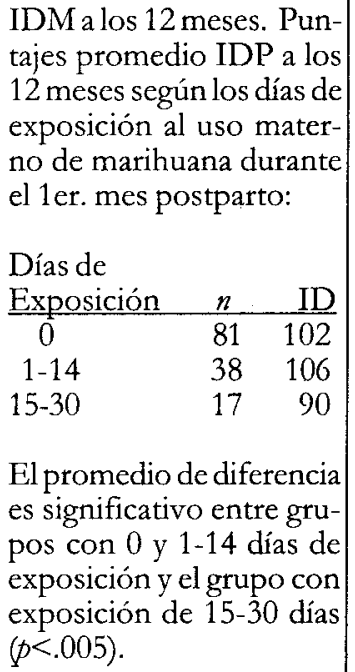 \\
\hline
\end{tabular}

Nota. IDM: Indice de Desarrollo Mental. IDP: Indice de Desarrollo Psicomotor. 


\section{La leche de pecho contaminada por drogas (por ej. alcohol, cocaína, marihuana) o por algunos contaminantes ambientales (por ej. pesticidas) demoran el desarrollo intelectual del niño.}

Esta sección intenta destacar la importancia política y programática que tiene la pregunta sobre el riesgo al que puede estar expuesto un niño amamantado cuando la madre consume o ha consumido drogas o a estado expuesta a contaminación ambiental. Limitaciones metodológicas y de diseño inherentes a la propia naturaleza temática previenen muchas veces tener el conocimiento suficiente para aconsejar a las madres sobre el amamantamiento en dichas situaciones, teniendo en cuenta que la falta de leche de pecho debilita la resistencia a las infecciones de los bebés.

\section{C.1. Drogas}

Aquí nos referimos exclusivamente a la transferencia del alcohol, cocaína y marihuana de la madre al niño a través de la leche de pecho. Si bien nuestro énfasis está en la lactancia es menester considerar que el consumo de drogas durante este período puede haber sido antecedido por el consumo durante la gestación. El efecto combinado en el desarrollo mental es probablemente mayor al causado por el consumo de drogas durante uno de estos dos períodos independientemente. Además el consumo de una droga en particular (por ejemplo, cocaína) puede estar asociado al consumo de otras drogas (por ejemplo, heroína). La simultaneidad e interacción entre las drogas puede tener efectos sinérgicos.

El consumo de alcohol durante el amamantamiento no siempre fue criticado. A principios de este siglo se le recomendaba a la madres que tomaran licor, particularmente cerveza, para aumentar la producción de leche y fortalecer al vástago. Algunas compañías ofrecían su producto como un medio de estimular el apetito de las madres, hacerlas mas fuertes, y estimular su producción láctea (revisar como ejemplos a Roth, 1879 y Falkner, 1987.) Estos avisos comerciales sin embargo carecen de sustento empírico. 
El alcohol es absorbido rápidamente por el organismo y entra en la circulación del feto y en la leche de pecho. El efecto prenatal incluye el retardo en el crecimiento intrauterino que resulta en un bajo peso al nacer $y$ en varias otras formas de patología fetal (Institute of Medicine, 1996). Menos se sabe sobre los efectos a través de la leche de pecho (exclusivamente). Esta diferencia en el conocimiento posiblemente se debe a la dificultad para aislar los efectos.

Un bebé que es amamantado consume menos leche de pecho que lo habitual cuatro a cinco horas después de que la madre ha tomado una bebida alcohólica. El mecanismo no es claro, pero es plausible que esté relacionado con un cambio producido por el etanol en el sabor de la leche de pecho. Es también plausible que la leche contaminada produzca efectos fisiológicos en el niño que incluyen una reducción en el tiempo de mamar (Mennelas, 1995; Mennela y Beauchamp, 1991 y 1993).

Dentro de los pocos estudios sobre el desarrollo se ha observado una modesta relación inversa entre el consumo del alcohol en la madre durante el período de amamantamiento y el desarrollo mental de los bebés a los 12 meses (Instituto de Medicina, 1996). Por ejemplo, los resultados del estudio de Little, Anderson, Ervin, Worthington-Roberts y Clarren (1989) mostraron que a los 12 meses de edad el promedio IDM de los niños cuyas madres tomaban alcohol era 5 puntos menor al promedio IDM de los niños que no fueron expuestos. La comparación de los puntajes en la prueba de desarrollo motor mostró una diferencia altamente significativa de 19 puntos y en la misma dirección que la hipótesis original (revisar también O'Connor, Sigman y Kasari, 1993).

Pese a la importancia social atribuida al consumo de las drogas por las agencias internacionales y gobiernos interesados, hay muy poca información científica consistente que ofrezca una imagen clara respecto de los efectos al desarrollo del niño producidos por la contaminación de la leche de pecho con cocaína o marihuana. Anecdóticamente, hemos oído frecuentemente afirmaciones respecto a dichos efectos sin ser fundamentados por información científicamente aceptable. 
Brevemente, no sabemos cuales pueden ser los efectos al niño de la cocaína y marihuana transferidas por la madre a través de la leche del pecho. Además, los datos obtenidos en adolescentes y adultos no pueden ser generalizados a los bebés. Aun cuando se demostrara definitivamente que no hay efectos en los sujetos de mayor edad no se puede concluir que no hay efectos en los bebés porque estos son más vulnerables.

\section{C.2. Contaminantes ambientales}

Muchas comunidades en diversas partes del mundo han estado expuestas a degradaciones ambientales temporales (por ejemplo, el incidente nuclear de Chernobyl en 1986) o a uno o mas compuestos químicos (por ejemplo, pesticidas clorinados) y minerales tóxicos (por ejemplo, mercurio) por largos períodos. Lo que aquí interesa es que la contaminación puede producir cambios en la leche de pecho que pone en riesgo el desarrollo del niño Jensen y Slorach, 1991; Sim y McNeill, 1992). Dentro de los contaminantes con ese potencial, los que se consideran de mayor peligro son aquellos que se depositan en la grasa del cuerpo siendo metabolizados lentamente y son movilizados para la producción de leche. Actualmente, se considera que los contaminantes mas peligrosos son los pesticidas clorinados, los bifenoles policlorinados y los dioxidos (Jensen y Slorach, 1991).

Como se observa en el caso de las drogas ya mencionadas, hay numerosos estudios sobre los efectos de los contaminantes en el crecimiento intrauterino pero no es así en el caso de los efectos mediados por la leche de pecho. Sin embargo, los pocos estudios existentes sugieren que este es un problema que requiere definición inmediata. Esto es particularmente cierto si se toma en consideración la posición de la Organización Mundial de la Salud (OMS). La OMS indica, por un lado, que se puede prevenir la contaminación de los bebés si las madres no amamantan al niño. Pero, por otro lado, la OMS indica que dicha acción es contraria a los intereses del niño ya que la mortalidad infantil puede disminuirse de manera substantiva a través de la lactancia en poblaciones donde la desnutrición es endémica y la mortalidad infantil es alta. Dadas estas 
consideraciones la OMS recomienda que la política debe ser apoyar y mantener el amamantamiento. Es más, la OMS afirma que no porque se detecte la presencia de un contaminante en la leche de pecho se debe pensar que el desarrollo del niño esta en riesgo (Asamblea Mundial de la Salud, 1994; Lutter, Iyengar, Barnes, Chuvakova, Kazbehova y Sharmanov, 1996; UNICEF, 1997).

\section{Discusión General}

La información presentada en este trabajo no es suficiente para responder definitivamente a las tres hipótesis con que partimos sobre los efectos del amamantamiento en el desarrollo mental de los niños. Las limitaciones son particularmente claras en el caso de la primera y la tercera hipótesis. Los estudios relacionados a la primera hipótesis han estado basados en correlaciones que, como ya se dijo, no permiten un control satisfactorio de las variables que pueden confundir la relación entre las dos variables que nos conciernen. Esta incertidumbre está también presente en lo que se refiere a la contaminación de la leche de pecho por drogas o por compuestos químicos y minerales tóxicos en el ambiente. El número de estudios que existen sobre estos temas es limitado y los que existen tienen serios problemas de diseño que impiden la discriminación entre efectos pre- $y$ postnatales y entre efectos producidos por el consumo simultáneo de varias drogas.

Los estudios que responden a la segunda hipótesis son los más convincentes. Además, estos estudios muestran con claridad la importancia biológica de la leche de pecho para un sano desarrollo del funcionamiento cerebral, particularmente en el caso del niño prematuro y de bajo peso al nacer. Por ello, la información es útil dentro del contexto de las políticas nacionales de salud pública en muchos de los países en América Latina donde el número de niños de bajo paso al nacer es elevado. Por ejemplo, un informe reciente de la Organización Panamericana de la Salud (Gonzales-Cossio, Rivera, Flores y Freire, 1997) informa que una encuesta de 1980 a 1989 en el Perú mostró que el 11\% de los niños nacen con un peso por debajo de los 2,500 gramos. Los niños de 
bajo peso son particularmente vulnerables a desarrollar problemas de aprendizaje y funcionamiento durante la edad escolar (Perez-Escamilla, Pollitt, Lonnerdal y Dewey, 1994).

La información disponible hoy sobre la importancia de los ácidos grasos esenciales en el desarrollo es probablemente solo una introducción a esta nueva línea de investigación. Los estudios sobre diversos aspectos de su relación con el funcionamiento del sistema nervioso central aumentan rápidamente y no debe sorprender que muy pronto se hagan descubrimientos fundamentales para entender la relación entre nutrición, cerebro y cognición.

No es fácil aceptar las recomendaciones de la Organización Mundial de la Salud de mantener el amamantamiento aun cuando haya información sobre la contaminación de la leche que puede afectar el desarrollo del niño. Este es el caso, por ejemplo, con los pesticidas clorinados que todavía se siguen usando en algunas regiones del mundo. Dentro de la información que tenemos hasta hoy no se han hecho los análisis epidemiológicos necesarios para determinar cuantitativamente los riesgos para el niño en forma particular y para la sociedad en general. Lamentablemente estos cálculos requieren datos que son muy difíciles y costosos de obtener en el contexto de poblaciones donde la pobreza es un sistema de vida. En nuestra opinión, el amamantamiento no es recomendable en situaciones donde la desnutrición no es un problema de salud pública y la madre consume persistentemente alcohol, cocaína o marihuana.

Este trabajo presenta muy sumariamente lo que sabemos sobre el amamantamiento y el desarrollo mental de los niños. Como se dijo inicialmente no intentamos presentar una revisión bibliográfica exhaustiva. Nuestra intención fue sólo presentar una imagen representativa del área. El resultado puede no haber sido definitivo como se hubiera deseado; pero en general la información indica que el amamantamiento debe ser el método indicado para alimentar a los bebés durante el primer año de vida. 


\section{Referencias}

Agostoni, C., Trojan, S., Bellu, R,, Riva, E. y Giovannini, M. (1995). Neuro-developmental quotient of healthy term infants at 4 months and feeding practice: the role of long-chain polyunsaturated fatty acids. Ped Res, 38, 262-266.

Asamblea Mundial de la Salud (1994). Infant and young cbild nutrition. Resolution 47.5 of the $47^{\text {th }}$ World Health Assembly, Geneva, May, 1994. Geneva: Organización Mundial de la Salud (W.H.O.).

Astleysty Little, R.E. (1990). Maternal marijuana use during lactation and infant development at one year. Neurotoxicology and teratology, 12, 161-168.

Birch, E., Birch, D., Hoffman, D., Hale, L., Everett, M. y Uauy, R. (1993). Breastfeeding and optimal visual development. J Pediatr Opthalmol Strabismus, 30, 33-38.

Cohen, R.J., Landa Rivera, L., Rivera, A., Lonnerdal, B., Brown, K.H. y Dewey, K. (1993). Anemia among breastfed infants at 6 months of age in Honduras. XV International Congress of Nutrition: Final Program and Abstract, 2, 158.

Colombo, J. (1993). Infant cognition: Predicting later intellectual functioning. Newbury Park: Sage Publications.

Falkner, F. (1987). Beer and the breast-feeding mom. Joumal of the American Medical Association, 258, 2126.

Fergusson, D.M., Beautrais, A.L., y Silva, P.A. (1982). Breastfeeding and cognitive development in the first seven years of life. Soc Sci Med, $16,1705-1708$.

Florey, C. du V., Leech, A.M. y Blackhall, A. (1995). Infant feeding and mental and motor development at 18 months of age in first born singletons. Intl J of Epid, 24, S21-S26.

González-Cossió, T., Rivera Dommarco, J., Flores, M. y Freire, W.B. (1997). Creciendo en las Americas: la Magnitud de la Desnutrición al Final del Siglo. Washington, DC: Organización Panamericana de la: Salud/ Organización Mundial de la Salud.

Hoefer, C. y Hardy, M.C. (1929). Later development of breastfed and artificially fed infants. Joumal of the American Medical Association, 92 (8), 615-619. 
Howie, P.W. (1996). Protective effect of breastmilk against infection. Food and Nutrition Bulletin, 17(4), 373-379.

Idjradinata, P. y Pollitt, E. (1993). Reversal of develop-mental delays in iron-deficient anaemic infants treated with iron. Lancet, 341 (8836), $1-4$.

Institute of Medicine (1990). Nutrition during Lactation. Food and Nutrition Board, National Academy of Sciences. Washington, D.C.: National Academy Press.

Institute of Medicine (1996). WIC Nutrition Risk Criteria: a Scientific Assessment. Committee on Scientific Evaluation of WIC Nutrition Risk Criteria, Food and Nutrition Board, National Academy of Sciences. Washington, D.C.: National Academy Press.

Jensen, A.A. y Slorach, S.A. (1991). Chemical contaminantes in buman milk. Boca Raton: CRC Press.

Knobloch, K.H., Pasamanick, B. y Sherard, E.S. (1966). A developmental screening inventory for infants. Pediatr, 38, 1095-1108.

Kotlezko, B. y Bremer, H.D. (1989). Fat content and fatty acid composition of infant formulae. Acta Paediatr Scand, 78, 513-521.

Lanting, C.I., Fidler, V., Huisman, M., Touwen, B.C.L. y Boersma, E.R. (1994). Neurological differences between 9-year-old children fed breast milk or formula-milk as babies. Lancet, 344, 1319-1322.

Little, R.E., Anderson, K.W., Ervin, C.H., Worthington-Roberts, B. y Clarren, S.K. (1989). Maternal alcohol use during breastfeeding and infant mental and motor development at one year. New England Journal of Medicine, 321(7), 425-430.

Lonnerdal, B. (1982). Iron and breast milk. Iron nutrition in infancy and childhood. Nestle Nutrition Workshop Series, 4, 95-114.

Lucas, A., Morley, R., Cole, T.J., Gore, S.M., Davis, J.A., Bamford, M.F.M. y Dossetor, J.F.B. (1989). Early diet in preterm babies and developmental status in infancy. Arch Dis Child, 64, 1570-1578.

Lucas A, Morley R, Cole TJ, Lister G. y Leeson-Payne C. (1992). Breast milk and subsequent intelligence quotient in children born preterm. Lancet, 339, 261-264.

Lucas, A., Morley, R., Cole, T.J. y Gore, S.M. (1994). A randomised multicentre study of human milk versus formula and later development in preterm infants. Arcb Dis Child, 70, F141-146. 
Lutter, C.K., Iyengar, V., Barnes, R., Chuvakova, T., Kazbehova, G. y Sharmanov, T. (1996). Breastmilk contamination in Kazakstan: Implications for infant feeding. Dioxin, 24-29.

McNeilley, A.S. (1996). Breastfeeding and the suppression of fertility. Food and Nutrition Bulletin, 17(4), 340-345.

Menkes, J.H. (1977). Early feeding history of children with learning disorders. Devel Med Child Neurol, 19, 169-171.

Mennella, J.A. (1995). Mother's milk: A medium for early flavor experiences. Joumal of Human Lactation, 11, 39-45.

Menella, J.A. y Beauchamp, G.K. (1991). The transfer of alcohol to human milk: Effects on flavor and the infant's behavior. New England Journal of Medicine, 325, 981-985.

Mennela, J.A. y Beauchamp, G.K. (1993). Beer, breast feeding and folklore. Developmental Psycbobiology, 26, 459-466.

Moffatt, M.E.K., Longstaffe, S., Beant, J. y Dureski, C. (1994). Prevention of iron deficiency and psychomotor decline in high-risk infants through use of iron-fortified infant formula: A randomized clinical trial. $J$ Pediatr, 125, 188-534.

Morrow-Tlucak, M., Haude, R.H. y Ernhart, C.B. (1988). Breastfeeding and cognitive development in the first 2 years of life. Sor Sci Med, 26 (6), 635-638.

O'Connor, Sigman y Kasari (1993). Interactional model for the association among maternal alcohol use, mother infant interaction, and infant cognitive development. Infant behavior and Development, 16, 177-292.

Perez-Escamilla, R., Pollitt, E., Lonnerdal, B. y Dewey, K.G. (1994). Infant feeding policies in maternity wards and their effect on breast-feeding success: an analytical overview. American Journal of Public Health, 84(1), 89-97.

Pollitt, E. (1993). Iron deficiency and cognitive function. En R.E. Olson, D.M. Blier y D.B. McCormick (Eds.), Annual Reviews in Nutrition. (pp. 521-537). Palo Alto, CA: Annual Reviews.

Pollitt, E. y Oh, S.-Y. (1994). Early supplementary feeding, child development and health policy. Food Nutrition Bulletin, 15(3), 208-214.

Rodgers, B. (1978). Feeding in infancy and later ability and attainment: a longitudinal study. Develop Med Child Neurol, 20, 421-426. 
Rogan, W.J. y Gladen, B.C. (1993). Breastfeeding and cognitive development. Early Human Development, 31, 181-193.

Roth, C.H.F. (1879). Infant feeding and its influence on life. Nueva York: William Wood and Company.

Sim, M.R. y McNeill, J.J. (1992). Monitoring chemical exposure in breastmilk: A methodological review. American Joumal of Epidemiology, 136, 1-11. Temboury, M.C., Otero, A., Polanco, I. y Arribás, E. (1994). Influence of breastfeeding on the infant's intellectual development. $J$ Pediatr Gastroenterol and Nutr, 18, 32-36.

Uauy, R. y Andraca, I. (1995). Human milk and breast feeding for optimal mental development. Journal of Nutrition, 125, 2278S-2280S.

Uauy, R., Birch, D., Birch, E., Tyson, J. y Hoffman, D. (1990). Effect of dietary omega- 3 fatty acids on retinal function of very low-birth weight neonates. Ped Res, 28, 485-492.

UNICEF (1997). Breasfeeding and Environmental Contamination: a Discussion Paper. Nueva York: UNICEF, Nutrition Section.

Young, H.B., Buckley, A.E., Hamza, B. y Mandarano, C. (1982). Milk and lactation: some social and developmental correlates among 1,000 infants. Pediatr, 69(2), 169-175. 